\title{
Identification of the basic leucine zipper transcription factor and analysis of expression responses to biotic and abiotic stresses in kiwifruit (Actinidia Lindl.)
}

\author{
Zhaobin Jing ${ }^{1,2}$ and Hongqi $\mathrm{Fu}^{2}$ \\ ${ }^{1}$ College of Horticulture, Northwest A\&F University, Yangling, Shaanxi, China \\ ${ }^{2}$ Weinan Vocational and Technical College, Weinan Fruit Industry Institute of Shaanxi, Weinan, Shaanxi, China
}

\begin{abstract}
Summary
The basic leucine zipper (bZIP) transcription factor family is involved in regulating organ differentiation, embryogenesis, flower and vascular development, seed maturation, and plays important roles in responding to biotic and abiotic stress. To date, bZIP gene family in kiwifruit (Actinidia spp.) remains poorly understood. In this study our objective was to identify the bZIP transcription factor of kiwifruit; in this study 80 AcbZIP genes were identified in the kiwifruit genome. Based on domain architecture and phylogenetic analyses, kiwifruit bZIP genes can be classified into ten superfamilies. Synteny analysis indicated that segmental duplication events contributed to the expansion of the kiwifruit AcbZIP family. In addition, the synteny analysis between kiwifruit and Arabidopsis suggested that some of the AcbZIP genes were derived from common ancestors before the divergence of these two genera. Conserved motifs outside the AcbZIP domain may reflect their functional conservation. Furthermore, the analysis of 16 Group A AcbZIP genes showed a variety of expression patterns in five different organs and suggested some potential genes during biotic and abiotic stresses. The genome-wide identification and characterization of kiwifruit bZIP transcription factors could facilitate functional analysis of these genes and provide important information of the molecular basis of development and stress tolerance in kiwifruit.
\end{abstract}

Keywords

genome-wide, kiwifruit, bZIP transcript factor, expression analysis

\section{Introduction}

Kiwifruit is one of the most important fruits in the world, and it is widely used in food production due to its high nutritional value. The native distribution of this genus is in China and southeastern Asia, and includes a genus of 55 species and 75 subspecific taxa (Huang and Ferguson, 2007). Recently, the quality and production of kiwifruit have been affected by some abiotic and biotic stresses. For example, bacterial canker of kiwifruit has influenced kiwifruit orchards in almost all areas of its production worldwide since 2008 . Plants need to adapt their growth process to abiotic and biotic stresses by internal gene expression and regulation. Transcriptomes play a large role in the regulatory networks and signal transduction of plant abiotic and biotic biological pro-

\section{Significance of this study}

What is already known on this subject?

- The basic leucine zipper (bZIP) family is one of the largest and most diverse transcription factor families in plants. bZIP family were identified in some plants. The availability of complete kiwifruit genome sequences allows the genome-wide identification of bZIP TFs.

\section{What are the new findings?}

- In this study, 80 AcbZIP genes have been identified in the kiwifruit genome. Synteny analysis indicated that segmental duplication events contributed to the expansion of the kiwifruit AcbZIP family. The analysis of AcbZIP genes showed a variety of expression patterns in five different organs and suggested some potential genes during biotic and abiotic stresses.

What is the expected impact on horticulture?

- We expected to provide reference and resources for studying functional analysis of AcbZIP genes and to provide important information of the molecular basis of development and stress tolerance in horticultural plants.

cesses (Rabara et al., 2013). The basic leucine zipper (bZIP) family is one of the largest and most diverse transcription factor families in plants (Zhao et al., 2016). The bZIP TFs are named according to the domain that contains a conserved 60-80 amino acids, which has two structural features: a basic region that binds DNA and a leucine zipper dimerization motif (Hurst, 1994; Talanian et al., 1990). The basic region contains a N-x7-R/K-x9 motif with about 18 amino acid residues, which are responsible for DNA binding and nuclear localization. The leucine zipper is composed of a heptad repeat of leucine residues or other bulky hydrophobic amino acids that involved recognition and dimerization of bZIP.

Numerous studies showed that bZIP TFs are involved in regulating organ differentiation (Silveira et al., 2007), embryogenesis, flower and vascular development (Guan et al., 2009; Zou et al., 2008), seed maturation (Jakovy et al., 2002). bZIP TFs also play important roles in responding to biotic and abiotic stress, including salt and drought (Huang et al., 2016; Zhao et al., 2016; Ying et al., 2012), low temperatures (Liu et al., 2012), osmotic stress (Weltmeier et al., 2006), and pathogens (Thurow et al., 2005). Increasing studies have also indicated that bZIP TFs take part in hormone and sugar sig- 
naling (Nieva et al., 2005), light treatment (Ulm et al., 2004), nitrogen/carbon metabolism (Wang et al., 2011). To date, a number of bZIP factors have been identified in some plants, such as 75 bZIP Arabidopsis thaliana (Jakoby et al., 2002), 89 in rice (Nijhawan et al., 2008), 88 in sorghum (Wang et al., 2011), 125 in maize (Wei et al., 2012), 100 in castor bean (Jin et al., 2014), 64 in cucumber (Baloglu et al., 2014), 55 in grape (Li et al., 2017; Gao et al., 2014), 112 or 144 in apple (Zhao et al., 2016), 136 in Chinese cabbage (Bai et al., 2016), and 77 in cassava (Hu et al., 2016).

Despite studies of the plant bZIP TFs from different plant species, only a few have been identified in tree or vine species. Based on the available genome sequences, the bZIP TFs had not yet been studied in the kiwifruit. The availability of complete kiwifruit genome sequences allows the genome-wide identification of bZIP TFs. In this study, our objective was to identify kiwifruit bZIP TFs based on the complete genome sequence of the diploid kiwifruit variety Hongyang. In addition, the phylogenetic relationships, exon-intron structures, synteny and expression profiles of selected bZIP genes in different tissues and under abiotic and biotic stresses were evaluated.

\section{Materials and methods}

\section{Plant material and treatments}

'Hongyang' (A. chinensis var. chinensis f. rufopulpa M.Z. Li) kiwifruit variety were used this study and cultivated in an experimental field at the College of Horticulture, Northwest A\&F University, Yangling, China $\left(34^{\circ} 20^{\prime} \mathrm{N}\right.$; $\left.108^{\circ} 24^{\prime} \mathrm{E}\right)$. Different tissues, including apical buds, young leaves, stems, flower buds, and fruits were collected from 'Hongyang' trees (aged 6 years) during the 2016 growing season. The 2-yearold 'Hongyang' kiwifruit seedlings were used for the exogenous hormone, salinity and drought stress and Pseudomonas syringae pv. actinidiae (Psa) inoculation treatments. These seedlings had been planted in $20-\mathrm{cm}$ diameter pots in the greenhouse of the experimental station at the College of Horticulture, Northwest A\&F University, Yangling, China.

The third to fifth fully expanded young leaves from the shoot apices were used for hormone treatments. Hormone treatments were carried out by spraying young leaves with $100 \mu \mathrm{M}$ gibberellins (GA), $100 \mu \mathrm{M}$ salicylic acid (SA), $50 \mu \mathrm{M}$ methyl jasmonate (MeJA), $300 \mu \mathrm{M}$ abscisic acid (ABA) and $0.5 \mathrm{~g} \mathrm{~L}^{-1}$ ethylene (Eth) as previously described (Zhao et al., 2016; Guo et al., 2014), and leaves samples were harvested at $1,12,24$, and $48 \mathrm{~h}$ after the initiation of the treatments and frozen immediately in liquid nitrogen and stored at $-80^{\circ} \mathrm{C}$. Leaves sprayed with sterile water and harvested at the same time were used as controls for hormone treatments. The salinity stress was performed by irrigating seedlings with $2 \mathrm{~L} 250 \mathrm{mM} \mathrm{NaCl}$ solution, and the seedlings irrigated with same value water were used as a control (Zhao et al., 2016; Guo et al., 2014). Leaves were harvested at 1, 12, 24, and $48 \mathrm{~h}$ post-treatment. The drought stress treatment was performed by withholding water, and young leaves of the seedlings were collected at 48,96 , and $168 \mathrm{~h}$ post-treatment. Subsequently, the stressed seedlings were rewatered to soil saturation and leaves were collected at $48 \mathrm{~h}$ after rewatering (R48). For the drought stress control, seedlings were watered to drip each day (Meng et al., 2016; Zhao et al., 2016; Guo et al., 2014). Pathogen treatment was performed using inoculating the young leaves of 'Hongyang' with Psa (Pseudomonas syringae pv. actinidiae) strain Psamx-9 (GenBank Assembly ID: KT731230) according to the method previously
SupPlementary TABle S1. The primer sequences used for semi-quantitative RT-PCR amplification of AcbZIP genes.

\begin{tabular}{|c|c|c|c|}
\hline Gene & $\begin{array}{c}\text { Product } \\
\text { size }\end{array}$ & & Primer $\left(5^{\prime}-3^{\prime}\right)$ \\
\hline \multirow[t]{2}{*}{ AcbZIP3 } & 231 & $\mathrm{~F}$ & TCAACTTCCAGGACTTTCTCG \\
\hline & & $\mathrm{R}$ & CAATATCAAACGGGTCAGCA \\
\hline \multirow[t]{2}{*}{ AcbZIP13 } & 245 & $\mathrm{~F}$ & GACGATGTGTGGAGGGAGAT \\
\hline & & $\mathrm{R}$ & АСTCCGTTCCCAAACCCTAC \\
\hline \multirow[t]{2}{*}{ AcbZIP15 } & 249 & $\mathrm{~F}$ & TTCAATTGCCTGGAAAAACC \\
\hline & & $\mathrm{R}$ & TTGAAGGTGGTTGTTGTTGC \\
\hline \multirow[t]{2}{*}{ AcbZIP20 } & 225 & $\mathrm{~F}$ & TGGAGAGACATAGCCACTGGT \\
\hline & & $\mathrm{R}$ & TGTGTGCTGACCCATCTGTT \\
\hline \multirow[t]{2}{*}{ AcbZIP21 } & 243 & $\mathrm{~F}$ & TTAATCGAAACCCAGGTCCA \\
\hline & & $\mathrm{R}$ & ACCGATCAGGACCCGAAT \\
\hline \multirow[t]{2}{*}{ AcbZIP22 } & 220 & $\mathrm{~F}$ & CAACCAATGACAAGGCCAAG \\
\hline & & $\mathrm{R}$ & GATGAAGCAACTGCTGCTGA \\
\hline \multirow[t]{2}{*}{ AcbZIP31 } & 219 & $\mathrm{~F}$ & GGGGTTAGATCATCACAGCAA \\
\hline & & $\mathrm{R}$ & CAGTGCACCACTTTGAACCA \\
\hline \multirow[t]{2}{*}{ AcbZIP34 } & 201 & $\mathrm{~F}$ & GTGTCGTCAGATGGGATGTG \\
\hline & & $\mathrm{R}$ & TTCAACTGTGTAGGCCTGCTT \\
\hline \multirow[t]{2}{*}{ AcbZIP35 } & 238 & $\mathrm{~F}$ & CCCAGTTCAACAGGCTCTTC \\
\hline & & $\mathrm{R}$ & AGCCTGTTTCCTTGCTCTTG \\
\hline \multirow[t]{2}{*}{ AcbZIP43 } & 237 & $\mathrm{~F}$ & ACGGGTCGTACCAGAACAAT \\
\hline & & $\mathrm{R}$ & CGGCACTCCAAACTCTCCTA \\
\hline \multirow[t]{2}{*}{ AcbZIP44 } & 246 & $\mathrm{~F}$ & GACGTTGTGTGGAGGGAGAT \\
\hline & & $R$ & САСТTCGTTCCСАAАСССТА \\
\hline \multirow[t]{2}{*}{ AcbZIP56 } & 211 & $\mathrm{~F}$ & CATCATTGGTATGGGCGTTT \\
\hline & & $R$ & ACCCATCATTGGTCCAGGT \\
\hline \multirow[t]{2}{*}{ AcbZIP61 } & 217 & $\mathrm{~F}$ & GCCACAACATCATAGGTACGG \\
\hline & & $\mathrm{R}$ & CCCATAATAGGTCCAGGGTCA \\
\hline \multirow[t]{2}{*}{ AcbZIP64 } & 222 & $\mathrm{~F}$ & CAACAGATGGGTCGGAACAT \\
\hline & & $\mathrm{R}$ & ACTGCTCGGTATAGGCATGG \\
\hline \multirow[t]{2}{*}{ AcbZIP68 } & 241 & $\mathrm{~F}$ & CCCGTAATGATTCAGCCCTA \\
\hline & & $\mathrm{R}$ & ATAGGCATGGGATTGGCATA \\
\hline \multirow[t]{2}{*}{ AcbZIP72 } & 216 & $\mathrm{~F}$ & TGAGTCAGGAGCCAGAGATG \\
\hline & & $\mathrm{R}$ & ССАТТССТССТTСААТTTСG \\
\hline
\end{tabular}

described (Jing et al., 2016; Zhao et al., 2015). Leaves sprayed with sterile water were used as a negative control, and leaves were collected at $24,48,72$, and $120 \mathrm{~h}$ post-inoculation. For all above treatments, at each time point of each treatment, six leaves from six different plants were mixed to form one sample, to be used later in the experiment. All experiments were repeated for three biological replicates.

\section{RNA extraction and cDNA synthesis}

The total RNA was isolated using the E.Z.N.A. ${ }^{\circledR}$ Plant RNA Kit (Omega Bio-Tek, Inc.) according to the manufacturer's protocol. The quality and quantity of RNA were assessed using electrophoresis on $1 \%$ agarose gels and a NanoDrop 1000 spectrophotometer (Thermo Scientific, Wilmington, DE, USA), respectively. $500 \mathrm{ng}$ total high quality RNA were used for the first-stand cDNA synthesis. The cDNA synthesis was performed using a TransCript ${ }^{\circledR}$ cDNA sample prep kit (TransGen Biotech, China). The cDNA products were then diluted six-fold and stored at $-40^{\circ} \mathrm{C}$ for the later semi-quantitative RT-PCT and real-time quantitative RT-PCR analysis. 


\section{Identification and analysis of the kiwifruit bZIP family}

The following approach was used to search kiwifruit bZIP transcription factor families. First, we obtained the kiwifruit bZIP TFs from the iTAK-Plant Transcription Factor \& Protein Kinase Identifier and Classifier Database (http://bioinfo.bti. cornell.edu/cgi-bin/itak/db_home.cgi). Then each protein sequence was examined for the presence of a BZIP domain based on the HMM of the SMART online tool (http://smart. embl-heidelberg.de/) (Letunic et al., 2012). All hits with an e-value less than 0.01 were collected. All non-redundant protein sequences encoding complete bZIP domains were selected as putative bZIP genes and the genes without a complete bZIP domain were discarded. Lastly, we obtained the cDNA, genes, proteins sequences, and the chromosomal location of selected kiwifruit bZIP TFs from the Kiwifruit Genome Database (http://bioinfo.bti.cornell.edu/cgi-bin/kiwi/search. cgi). The information of $A$. thaliana bZIP TFs was downloaded from the TAIR database (http://www.arabidopsis.org/).

\section{Multiple sequence alignment and phylogenetic analysis of the kiwifruit bZIP genes}

Multiple sequence alignments of a total of 80 selected AcbZIP proteins were completed by DNAMAN software (Version 6.0). Then, multiple sequence alignments of the bZIP proteins of kiwifruit and A. thaliana were performed using ClustalW program (http://www.ebi.ac.uk/Tools). Phylogenetic trees were constructed using the MEGA 7.0 software with the neighbor-joining (NJ) method and a 1000 replicates of the bootstrap test. Arabidopsis bZIP domains of different subgroups were used as references to class the kiwifruit bZIP proteins. According to the multiple sequence alignments and the classification of AtbZIP (Arabidopsis) TFs, the AcbZIP TFs were assigned to corresponding groups and subgroups.

\section{Exon-intron structure analysis, distribution of conserved motifs in kiwifruit bZIP genes}

The exon-intron structures of the kiwifruit AcbZIP TFs were analyzed by the Gene Structure Display Server online tool (http://gsds.cbi.pku.edu.cn/) with all 80 CDS and the corresponding genomic sequences (Hu et al., 2015). Structure motif analysis were analyzed using the online MEME tool (http://meme-suite.org/tools/meme). All 80 AcbZIP protein sequences were put in as a file, and the parameters were set by optimum motif width $\geq 6$ and $\leq 200$, and the maximum number of motifs to limit 20.

\section{Synteny analysis of kiwifruit bZIP genes}

Tandem duplicated genes are defined as adjacent homologous AcbZIP genes on the single chromosome, with no more than one intervening gene (Guo et al., 2014). The specific chromosome location of each AcbZIP gene were analyzed in order to estimate whether or not a gene resulting from a tandem duplication. For synteny analysis, synteny blocks within kiwifruit genome and between kiwifruit and Arabidopsis genomes were downloaded from the plant Genome Duplication Database (http://chibba.agtec.uga.edu/duplication/). Then, the genes of the synteny blocks were identified and analyzed. The diagram of synteny analysis were generated by the Circos program (http://circos.ca/). The synonymous (Ks) and non-synonymous (Ka) nucleotide substitutions between orthologous gene pairs were obtained from iTAK Database 16.03 (http://bioinfo.bti.cornell.edu/cgi-bin/itak/db_home. cgi). The chromosome localization of AcbZIP genes was analyzed using MapInspect based on the information of gene physical position in the kiwifruit genome.

\section{Semi-quantitative RT-PCR and real-time PCR analysis}

The kiwifruit ACT 2 gene (GenBank Accession number EF063572) amplified with the primers $F\left(5^{\prime}\right.$-GCAGGAATCCATGAGACTACC-3') and R(5'-GCAGGAATCCATGAGACTACC-3'), $18 S 2$ gene (GenBank Accession number AF419792) amplified with the primers F (5'-CTGTGAAACTGCGAATGGCTC-3') and R (5'-TTCCAGAAGTCGGGGTTTGT-3') was used the reference gene for accurate normalization of real-time quantitative PCR data (Ferradás et al., 2016). Other gene-specific primers were designed using Primer 5.0 (Premier Biosoft International) based on the corresponding CDS sequences (Supplementary Table S1). Semi-quantitative RT-PCR amplification reactions were carried out according to previously established protocols by Zhao et al. (2016) in $20 \mu \mathrm{L}$ volume, containing $1 \mu \mathrm{L}$ of template cDNA, $0.8 \mu \mathrm{L}$ of each primer, $10 \mu \mathrm{L} 2 \times$ TranStart $^{\circledR}$ RTip Green qPCR Super Mix (TransGen Biotech, China), and 7.4 $\mu \mathrm{L}$ sterile distilled water. PCR amplification was performed under the following conditions: $94^{\circ} \mathrm{C}$ for $3 \mathrm{~min}, 28-35$ cycles of $94^{\circ} \mathrm{C}$ for $30 \mathrm{~s}, 55-60^{\circ} \mathrm{C}$ for $30 \mathrm{~s}, 72^{\circ} \mathrm{C}$ for $30 \mathrm{~s}$ and $72^{\circ} \mathrm{C}$ for $5 \mathrm{~min}$. Semi-quantitative RT-PCR products were separated on $1.5 \%(\mathrm{w} / \mathrm{v})$ agarose gels and detected by ethidium bromide and photographed under UV light. PCR was repeated three times with the purpose of testing the same trends for each gene and treatment. Then expression data were recorded, analyzed and visualized by GeneSnap and Mev (Guo et al., 2014).

Real-time PCR analysis was conducted with an ABI real-time PCR instrument (ABI Step One Plus). Each reaction was carried out in triplicate with a reaction volume of $20 \mu \mathrm{l}$ containing $1.0 \mu \mathrm{l}$ of cDNA, $0.8 \mu \mathrm{l}$ each primer $(1.0 \mu \mathrm{M}), 10 \mu \mathrm{l}$ of SYBR green Passive Reference Dye $0.4 \mu \mathrm{l}$ (TransGen Biotech, China), and $7.4 \mu \mathrm{l}$ sterile distilled water. The PCR amplification parameters were $95^{\circ} \mathrm{C}$ for $30 \mathrm{~s}$, followed by 40 cycles of $95^{\circ} \mathrm{C}$ for $5 \mathrm{~s}$ and $60^{\circ} \mathrm{C}$ for $30 \mathrm{~s}$. Melt-curve analyses were performed using a program with $95^{\circ} \mathrm{C}$ for $15 \mathrm{~s}$ and then a constant increase from $60^{\circ} \mathrm{C}$ to $95^{\circ} \mathrm{C}$. The kiwifruit reference genes $18 S 2$ and ACT 2 were used as the internal reference genes. For each assay, three independent biological replications were performed. Relative expression levels were analyzed using the ABI software and the normalized expression $\Delta \mathrm{C}_{\mathrm{t}}$ method.

\section{Statistical analysis}

Statistical analysis was performed using Tukey's $t$ test. All experiments were carried out in triplicate and the results were expressed as mean \pm SD.

\section{Results}

\section{bZIP genes identification in kiwifruit}

To identify bZIP gene family in the kiwifruit genome, the HMM profile of the bZIP domain (PF00170) was found from the Pfam database. We used the SMART tool to test the bZIP domain with e-value less than 0.01 for each matching sequence, resulting a total of 80 potential genes that could be annotated as kiwifruit bZIP TFs. The 80 kiwifruit bZIP genes were named AcbZIP1 to AcbZIP80 according to their locations on the chromosomes 1 to 29. Of them, eighteen AcbZIP genes (Achn388061, Achn131571, Achn131971, Achn165061, Achn096961, Achn227711, Achn245851, Achn289881, Achn253991, Achn279821, Achn335331, Achn344281, Achn016621, Achn032501, Achn032491, Achn033861, Achn041161, Achn058051) could not be mapped to any chromosome, and were renamed AcbZIP63 to AcbZIP80. The information for 80 AcbZIP TFs was listed in Supplementary 
SuPPLEMENTARY TABLE S2. The information of AcbZIP gene families in kiwifruit.

\begin{tabular}{|c|c|c|c|c|c|c|c|c|}
\hline Group & Gene ID & Gene locus ID & Chromosome & CDS & ORF & Full length & Start site & End site \\
\hline \multirow[t]{16}{*}{ Group A } & AcbZIP3 & Achn076181 & 1 & 519 & 172 & 519 & $2,470,965$ & $2,471,483$ \\
\hline & AcbZIP13 & Achn305211 & 4 & 864 & 287 & 958 & $5,205,236$ & $5,206,193$ \\
\hline & AcbZIP15 & Achn158851 & 4 & 1191 & 396 & 3986 & $9,470,943$ & $9,474,928$ \\
\hline & AcbZIP20 & Achn315671 & 5 & 1191 & 396 & 3986 & $4,716,539$ & $4,720,524$ \\
\hline & AcbZIP21 & Achn296661 & 5 & 975 & 324 & 10832 & $18,725,958$ & $18,736,789$ \\
\hline & AcbZIP22 & Achn233651 & 6 & 1347 & 448 & 2019 & $16,332,232$ & $16,334,250$ \\
\hline & AcbZIP31 & Achn026271 & 11 & 1380 & 459 & 4307 & $1,539,809$ & $1,544,115$ \\
\hline & AcbZIP34 & Achn120161 & 12 & 3372 & 1123 & 11808 & $5,314,924$ & $5,326,731$ \\
\hline & AcbZIP35 & Achn173651 & 12 & 1290 & 429 & 6656 & $8,407,833$ & $8,414,488$ \\
\hline & AcbZIP43 & Achn091811 & 20 & 1197 & 398 & 2055 & $5,853,994$ & $5,856,048$ \\
\hline & AcbZIP44 & Achn290761 & 21 & 930 & 309 & 5152 & $7,204,386$ & $7,209,537$ \\
\hline & AcbZIP56 & Achn068551 & 26 & 960 & 319 & 2615 & $12,000,664$ & $12,003,278$ \\
\hline & AcbZIP61 & Achn200201 & 28 & 960 & 319 & 1919 & $11,291,432$ & $11,293,350$ \\
\hline & AcbZIP64 & Achn131571 & Unknown & 1296 & 431 & 4897 & $1,987,609$ & $1,992,505$ \\
\hline & AcbZIP68 & Achn227711 & Unknown & 1236 & 411 & 4046 & $57,279,469$ & $57,283,514$ \\
\hline & AcbZIP72 & Achn279821 & Unknown & 699 & 232 & 3661 & $71,591,190$ & $71,594,850$ \\
\hline \multirow[t]{2}{*}{ Group B } & AcbZIP10 & Achn328331 & 3 & 2424 & 807 & 5636 & $12,999,243$ & $13,004,878$ \\
\hline & AcbZIP75 & Achn016621 & Unknown & 2415 & 804 & 5118 & $117,298,859$ & $117,303,976$ \\
\hline \multirow[t]{4}{*}{ Group C } & AcbZIP4 & Achn040871 & 1 & 819 & 272 & 2689 & $11,509,065$ & $11,511,753$ \\
\hline & AcbZIP33 & Achn124481 & 11 & 1008 & 335 & 6184 & $7,809,687$ & $7,815,870$ \\
\hline & AcbZIP67 & Achn096961 & Unknown & 972 & 323 & 11506 & $31,641,397$ & $31,652,902$ \\
\hline & AcbZIP71 & Achn253991 & Unknown & 888 & 295 & 6497 & $65,705,973$ & $65,712,469$ \\
\hline \multirow[t]{8}{*}{ Group D } & AcbZIP1 & Achn094351 & 1 & 1878 & 625 & 17275 & 873,057 & 890,331 \\
\hline & AcbZIP29 & Achn136681 & 9 & 1128 & 375 & 8067 & $7,364,137$ & $7,372,203$ \\
\hline & AcbZIP32 & Achn284361 & 11 & 1080 & 359 & 3707 & $4,860,844$ & $4,864,550$ \\
\hline & AcbZIP36 & Achn126871 & 12 & 1284 & 427 & 8159 & $10,258,742$ & $10,266,900$ \\
\hline & AcbZIP52 & Achn251821 & 25 & 762 & 253 & 9986 & $7,251,652$ & $7,261,637$ \\
\hline & AcbZIP58 & Achn170521 & 27 & 735 & 244 & 14501 & $3,334,509$ & $3,349,009$ \\
\hline & AcbZIP62 & Achn085011 & 28 & 648 & 215 & 6426 & $13,981,520$ & $13,987,945$ \\
\hline & AcbZIP63 & Achn388061 & Unknown & 1095 & 364 & 3477 & 565,935 & 569411 \\
\hline Group E & AcbZIP73 & Achn335331 & Unknown & 981 & 326 & 3507 & $90,412,479$ & $90,415,985$ \\
\hline \multirow[t]{3}{*}{ Group F } & AcbZIP23 & Achn340941 & 7 & 810 & 269 & 810 & 573,431 & 574,240 \\
\hline & AcbZIP26 & Achn112471 & 8 & 741 & 246 & 741 & $6,148,444$ & $6,149,184$ \\
\hline & AcbZIP70 & Achn289881 & Unknown & 804 & 267 & 804 & $60,384,386$ & $60,385,189$ \\
\hline \multirow[t]{8}{*}{ Group G } & AcbZIP18 & Achn254431 & 5 & 1884 & 627 & 26461 & 335,865 & 362,325 \\
\hline & AcbZIP40 & Achn278691 & 14 & 1164 & 387 & 3227 & $6,650,726$ & $6,653,952$ \\
\hline & AcbZIP41 & Achn184611 & 15 & 1128 & 375 & 11514 & 667,704 & 679,217 \\
\hline & AcbZIP53 & Achn331511 & 25 & 855 & 284 & 4599 & $10,023,108$ & $10,027,706$ \\
\hline & AcbZIP54 & Achn096361 & 25 & 1065 & 354 & 10294 & $12,246,127$ & $12,256,420$ \\
\hline & AcbZIP55 & Achn084391 & 26 & 816 & 271 & 8699 & $5,091,573$ & $5,100,271$ \\
\hline & AcbZIP59 & Achn210631 & 27 & 945 & 314 & 7818 & $4,588,001$ & $4,595,818$ \\
\hline & AcbZIP69 & Achn245851 & Unknown & 1119 & 372 & 3195 & $60,031,511$ & $60,034,705$ \\
\hline \multirow[t]{4}{*}{ Group H } & AcbZIP42 & Achn159901 & 20 & 666 & 221 & 4925 & $1,697,134$ & $1,702,058$ \\
\hline & AcbZIP76 & Achn032501 & Unknown & 222 & 73 & 4947 & $118,502,354$ & $118,507,300$ \\
\hline & AcbZIP77 & Achn032491 & Unknown & 387 & 128 & 5054 & $118,524,549$ & $118,529,602$ \\
\hline & AcbZIP80 & Achn058051 & Unknown & 1038 & 345 & 7706 & $135,425,791$ & $135,433,496$ \\
\hline
\end{tabular}


SuPPlementary TABLE S2. (Continued).

\begin{tabular}{|c|c|c|c|c|c|c|c|c|}
\hline Group & Gene ID & Gene locus ID & Chromosome & CDS & ORF & Full length & Start site & End site \\
\hline \multirow[t]{12}{*}{ Group I } & AcbZIP5 & Achn327671 & 1 & 1542 & 513 & 4405 & $13,498,771$ & $13,503,175$ \\
\hline & AcbZIP6 & Achn251071 & 2 & 954 & 317 & 4121 & $2,308,680$ & $2,312,800$ \\
\hline & AcbZIP8 & Achn054841 & 3 & 1029 & 342 & 4409 & $1,540,811$ & $1,545,219$ \\
\hline & AcbZIP9 & Achn062651 & 3 & 1092 & 363 & 4795 & $11,015,733$ & $11,020,527$ \\
\hline & AcbZIP12 & Achn121041 & 4 & 1065 & 354 & 4925 & $4,373,887$ & $4,378,811$ \\
\hline & AcbZIP16 & Achn049341 & 4 & 1653 & 550 & 7279 & $10,535,621$ & $10,542,899$ \\
\hline & AcbZIP24 & Achn340751 & 7 & 1689 & 562 & 3519 & 976,206 & 979,724 \\
\hline & AcbZIP27 & Achn237931 & 8 & 1227 & 408 & 15806 & $11,547,744$ & $11,563,549$ \\
\hline & AcbZIP38 & Achn214181 & 13 & 1593 & 530 & 3250 & $7,226,747$ & $7,229,996$ \\
\hline & AcbZIP46 & Achn230471 & 21 & 1002 & 333 & 7686 & $12,153,876$ & $12,161,561$ \\
\hline & AcbZIP51 & Achn147981 & 24 & 1065 & 354 & 4393 & $13,104,660$ & $13,109,052$ \\
\hline & AcbZIP78 & Achn033861 & Unknown & 1602 & 533 & 3586 & $121,934,667$ & $121,938,252$ \\
\hline \multirow[t]{22}{*}{ Group S } & AcbZIP2 & Achn135561 & 1 & 447 & 148 & 447 & $1,695,035$ & $1,695,481$ \\
\hline & AcbZIP7 & Achn293811 & 2 & 495 & 164 & 495 & $11,421,641$ & $11,422,135$ \\
\hline & AcbZIP11 & Achn057151 & 3 & 408 & 135 & 5214 & $15,005,760$ & $15,010,973$ \\
\hline & AcbZIP17 & Achn049201 & 4 & 474 & 157 & 474 & $10,931,787$ & $10,932,260$ \\
\hline & AcbZIP14 & Achn249321 & 4 & 465 & 154 & 3137 & $8,351,591$ & $8,354,727$ \\
\hline & AcbZIP19 & Achn062291 & 5 & 591 & 196 & 591 & $4,560,105$ & $4,560,695$ \\
\hline & AcbZIP25 & Achn006801 & 7 & 444 & 147 & 444 & $1,325,736$ & $1,326,179$ \\
\hline & AcbZIP28 & Achn201271 & 9 & 447 & 148 & 447 & $4,545,207$ & $4,545,653$ \\
\hline & AcbZIP30 & Achn025721 & 11 & 363 & 120 & 363 & 876,192 & 876,554 \\
\hline & AcbZIP39 & Achn035031 & 13 & 612 & 203 & 2494 & $7,666,788$ & $7,669,281$ \\
\hline & AcbZIP37 & Achn229321 & 13 & 438 & 145 & 438 & 325,678 & 326,115 \\
\hline & AcbZIP45 & Achn015171 & 21 & 558 & 185 & 2523 & $12,079,122$ & $12,081,644$ \\
\hline & AcbZIP47 & Achn059341 & 22 & 393 & 130 & 393 & $11,613,437$ & $11,613,829$ \\
\hline & AcbZIP49 & Achn024761 & 23 & 438 & 145 & 438 & $20,599,729$ & $20,600,166$ \\
\hline & AcbZIP48 & Achn355201 & 23 & 705 & 234 & 2674 & $5,271,751$ & $5,274,424$ \\
\hline & AcbZIP50 & Achn103311 & 24 & 399 & 132 & 399 & $1,097,701$ & $1,098,099$ \\
\hline & AcbZIP57 & Achn170171 & 27 & 567 & 188 & 567 & $2,124,198$ & $2,124,764$ \\
\hline & AcbZIP65 & Achn131971 & Unknown & 456 & 151 & 456 & $2,601,369$ & $2,601,824$ \\
\hline & AcbZIP66 & Achn165061 & Unknown & 435 & 144 & 855 & $5,437,155$ & $5,438,009$ \\
\hline & AcbZIP74 & Achn344281 & Unknown & 429 & 142 & 3287 & $94,441,515$ & $94,444,801$ \\
\hline & AcbZIP79 & Achn041161 & Unknown & 567 & 188 & 567 & $126,599,061$ & $126,599,627$ \\
\hline & AcbZIP60 & Achn338531 & 27 & 591 & 196 & 591 & $8,306,869$ & $8,307,459$ \\
\hline
\end{tabular}

Table S2, including the group, subgroup, gene locus ID, the start sites and end sites of chromosome distribution, fulllength sequences, the length coding (CDS) and ORF sequences. A multiple sequence alignment of 80 AcbZIP genes was performed based on the core bZIP domain using DNAMAN software, including approximated 40 to 80 amino acids for each AcbZIP gene (Supplementary Figure S1).

\section{Phylogenetic analysis of kiwifruit and Arabidopsis bZIP genes}

The phylogenetic relationships of different plants can help to perform the classification of the AcbZIP gene family. As a model plant, Arabidopsis is commonly used to predict the function of a gene in a research plant. The phylogenetic relationship of 80 AcbZIP genes with AtbZIP genes from Arabidopsis was analyzed using the neighbor-joining algorithm, and all Arabidopsis AtbZIP proteins were added as reference proteins. The protein sequences of their full-length AcbZIP protein sequences were used for evolutionary relationships analysis. According to the results of phylogenetic tree, the AcbZIP genes were clustered into 10 distinct groups (A, B, C,
D, E, F, G, H, I, S) based on the features of AcbZIP proteins (Figure 1).

\section{Sequence and structure analyses of kiwifruit bZIP genes}

The unrooted phylogenetic tree was constructed based on the multiple sequence alignment of 80 kiwifruit AcbZIP protein domains (Figure 2A), and 80 AcbZIP genes were clustered into ten different groups. Exon-intron structure of the 80 AcbZIP genes were analyzed using the genome sequences and coding sequences (Figure 2B). As shown in Figure 3B, most of the AcbZIP genes shared a similar structure of exon-intron in the same group with some exception. For example, AcbZIP5, AcbZIP6, AcbZIP8, AcbZIP9, AcbZIP12, AcbZIP16, AcbZIP24, AcbZIP27, AcbZIP38, AcbZIP51, AcbZIP78 genes had three introns in group I, while other groups were similar within each group. A total of 59 AcbZIP genes include one to thirteen introns, which accounted for $73.75 \%$ of the total number of AcbZIP genes. In addition, 21 AcbZIP genes had been found no introns, which located in groups $\mathrm{F}$ and $\mathrm{S}$. The conserved motifs of 80 kiwifruit AcbZIP genes were analyzed using the MEME program (Figure 2C). As shown in Figure 3C, 


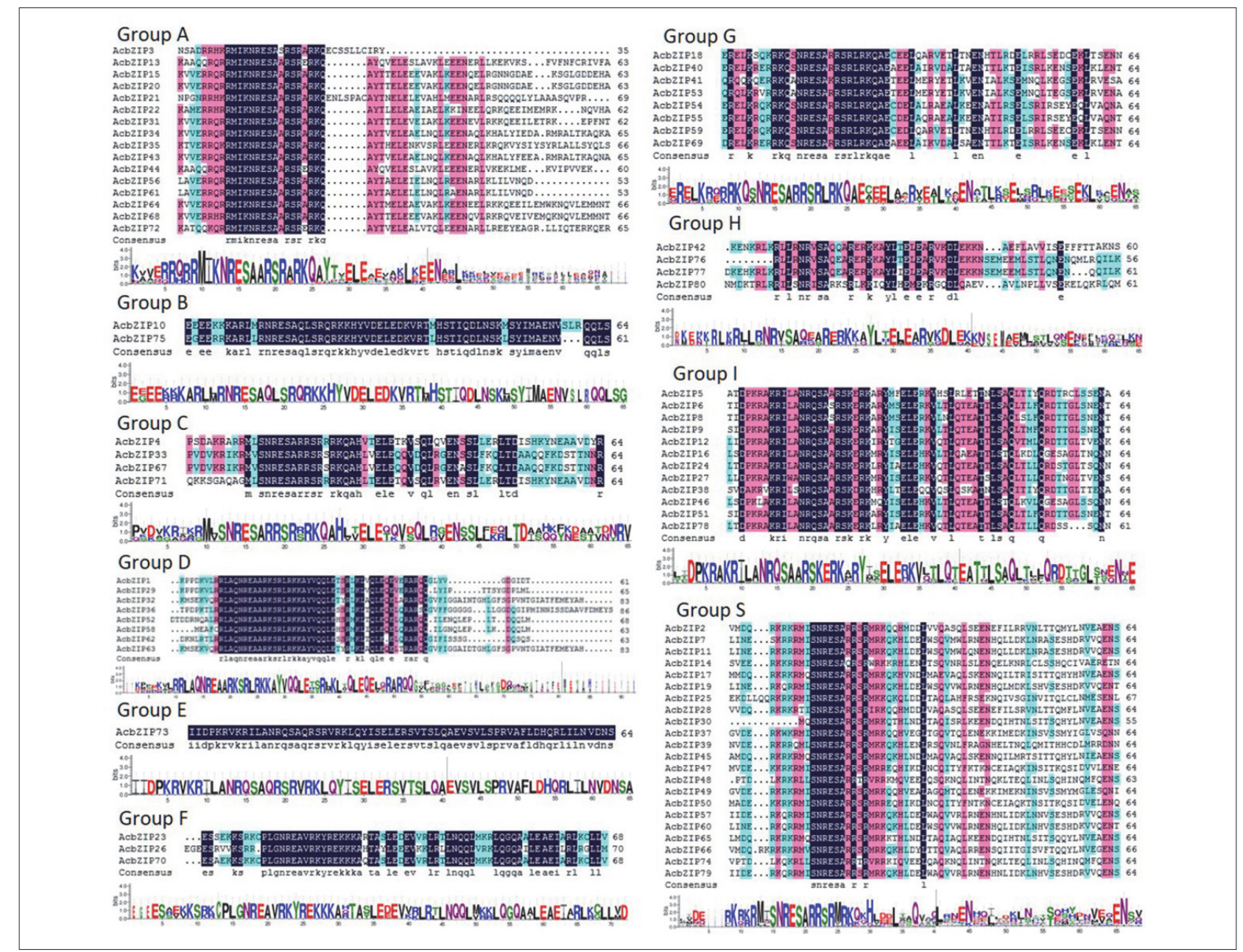

FIGURE S1. Multiple sequence alignment of the bZIP domain for kiwifruit bZIP genes. Blue indicates conserved amino acid domains. Full stope indicates gaps. The sequence conservations of each position were shown using the overall height in each stack, and each residue letter height is in proportion to the relative frequency of the corresponding residue.

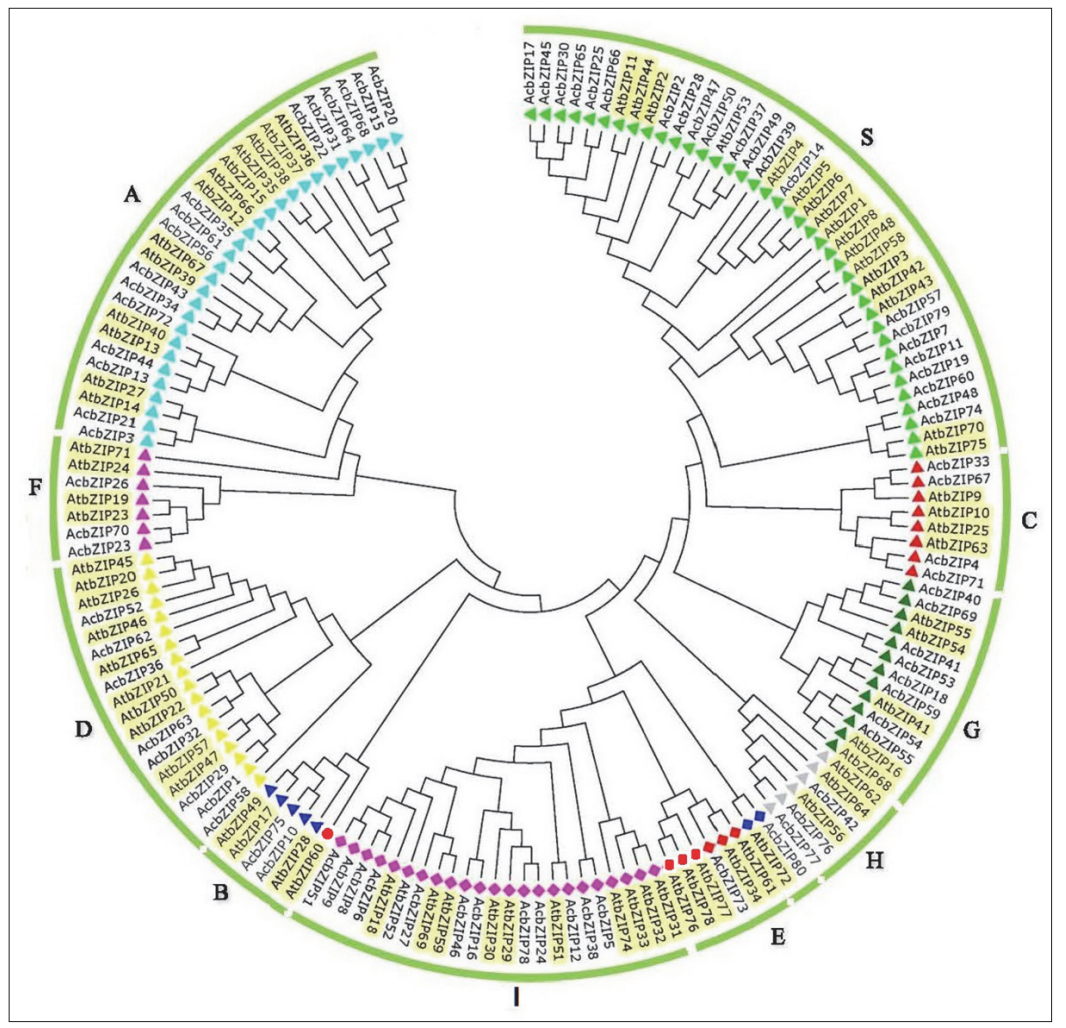

FIGURE 1. Phylogenetic tree of identified AcbZIP kiwifruit genes (black). Selected Arabidopsis AtbZIP (yellow) were representatives for the different groups. 
20 motifs were found (Supplementary Figure S2 and Table S3), and these genes were clustered in the same group that have a similar motif structure. All 80 AcbZIP genes contained a conserved basic leucine zipper amino acid domain (Motif 1), excluding AcbZIP21, AcbZIP30, AcbZIP 76. And almost all had more than one motif. The 80 AcbZIP TFs were distributed in all 29 kiwifruit chromosomes except for 10,16, 17, 18, 19 and 29 chromosomes, with chromosome 4 including the highest percentage (6.19\%) (Supplementary Figure 3).

\section{Tandem duplication and synteny analysis of $A c b Z I P$} genes

In order to analyze the expansion patterns of the kiwifruit AcbZIP gene family, the tandem duplication events of the 80 AcbZIP genes on the 23 kiwifruit chromosomes (Figure 3) were identified according to their physical location of each AcbZIP gene on its individual chromosome. In this study, AcbZIP genes with tandem duplication events were defined as a chromosomal region within $0.2 \mathrm{Mb}$ containing two or more genes (Guo et al., 2014). Only four AcbZIP genes (AcbZIP19 and AcbZIP20, AcbZIP45 and AcbZIP46) were

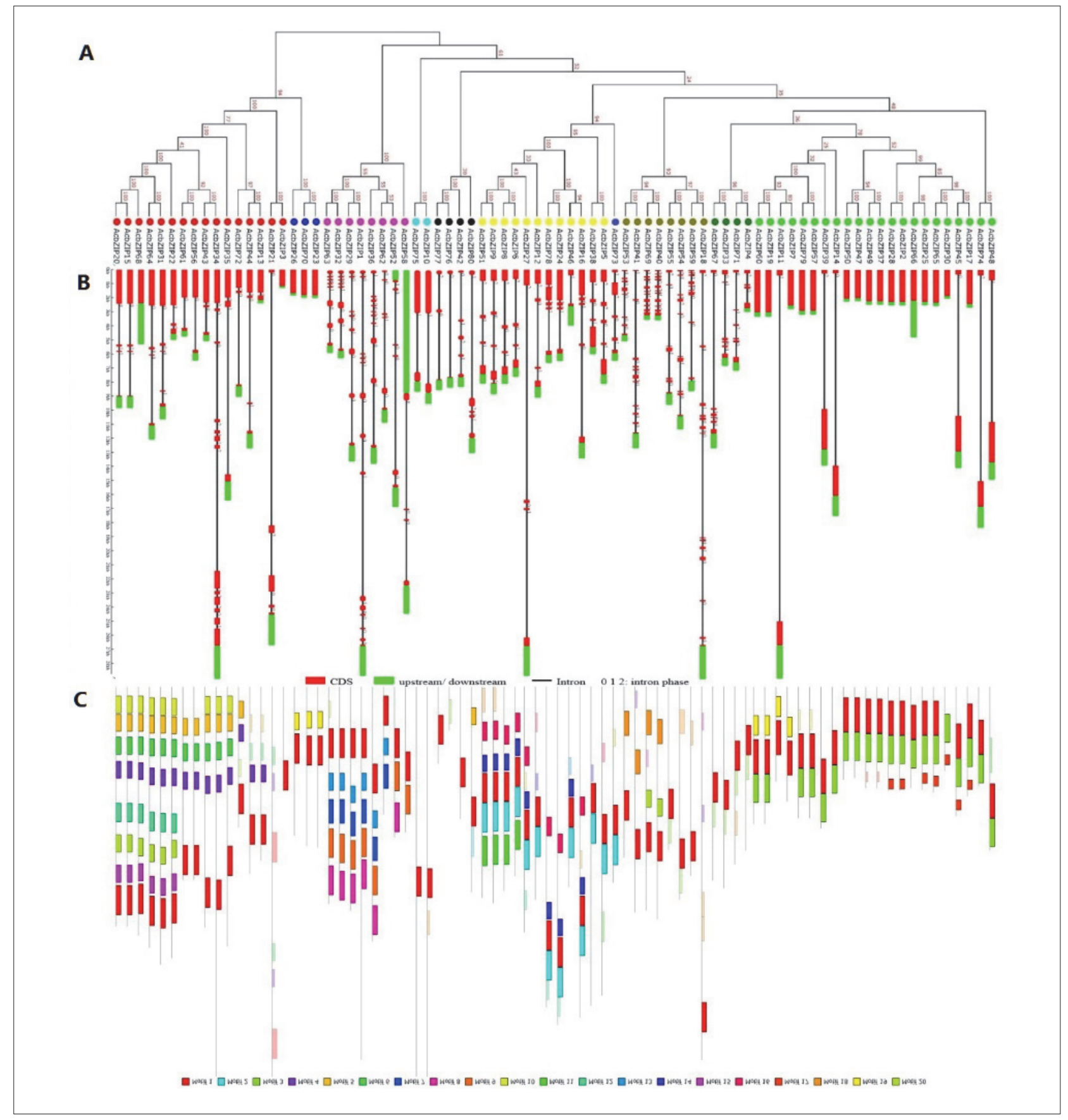

Figure 2. Structure characterization of kiwifruit AcbZIP genes. (A) Phylogenetic analysis of kiwifruit AcbZIP genes. (B) Intron/ Exon structure of kiwifruit AcbZIP genes, green indicates exons; black indicates introns; red indicates upstream or downstream. (C) Distribution of conserved motifs in the 80 AcbZIP genes. Each motif is represented by a colored box. 


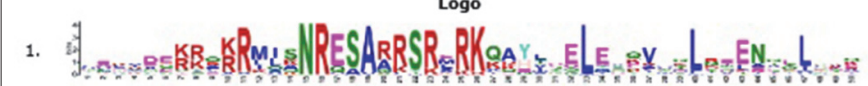

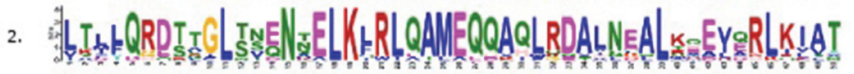

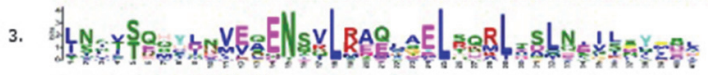

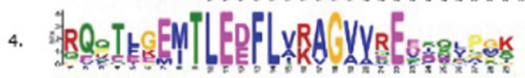

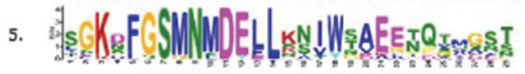

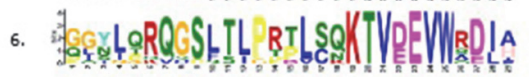

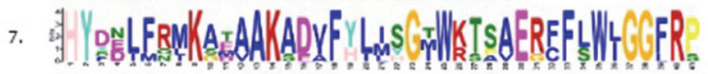

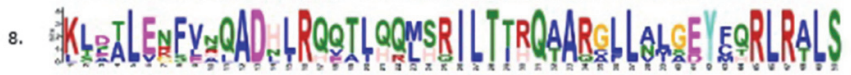

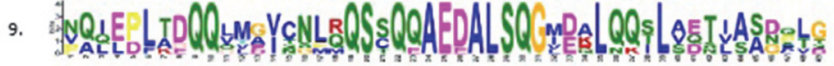

10.

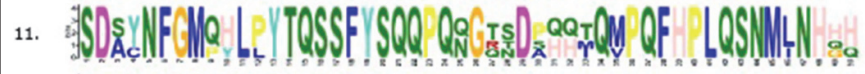

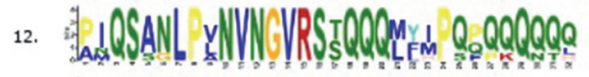

13. $A T$ ATE

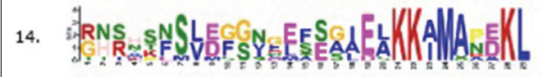

15. ANDGRESSNGDSSYS Y YPNGGLRGRK

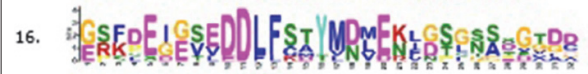

17. MNSWNEN

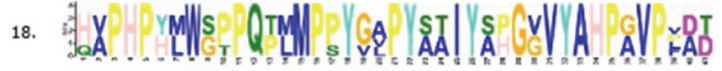

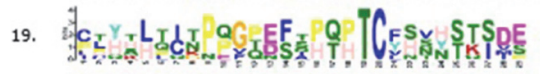

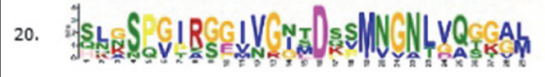

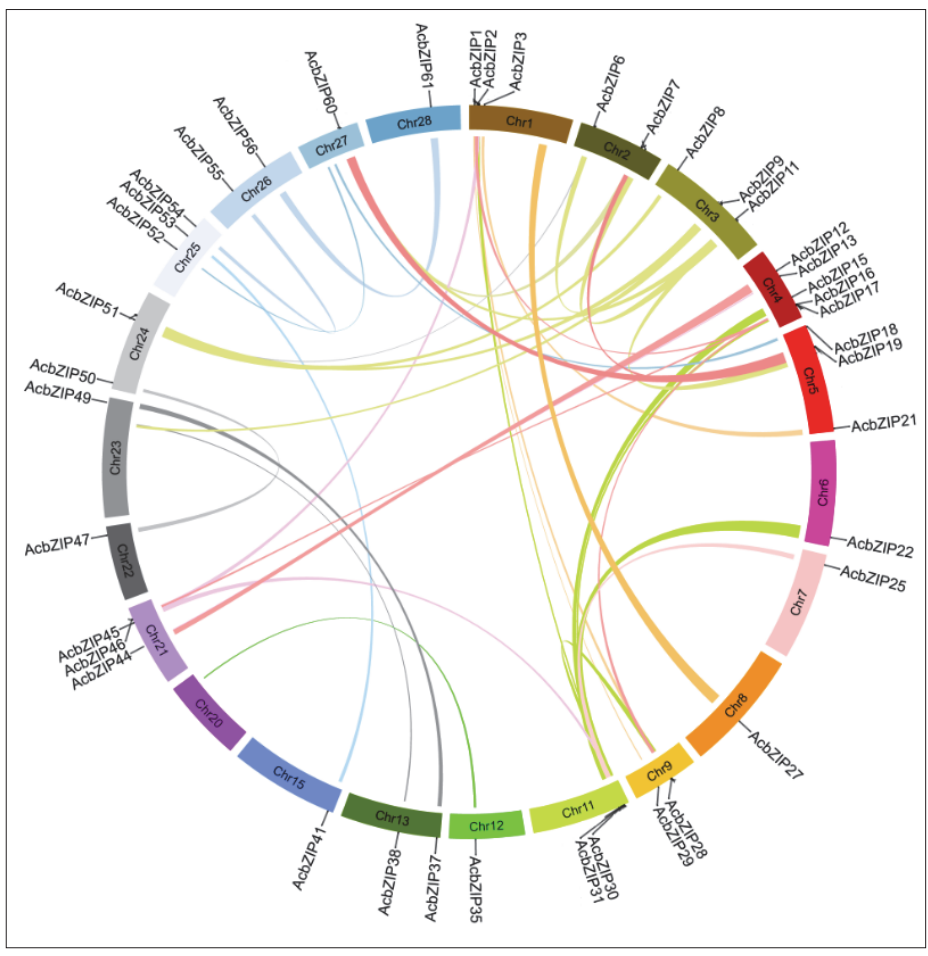

FIGURE S2. The logo of each motif of 80 AcbZIP genes.

FIGURE 3. Synteny analysis of kiwifruit AcbZIP genes. AcbZIP genes are indicated by vertical black lines. Colored lines connect the syntenic regions between kiwifruit bZIP genes. 


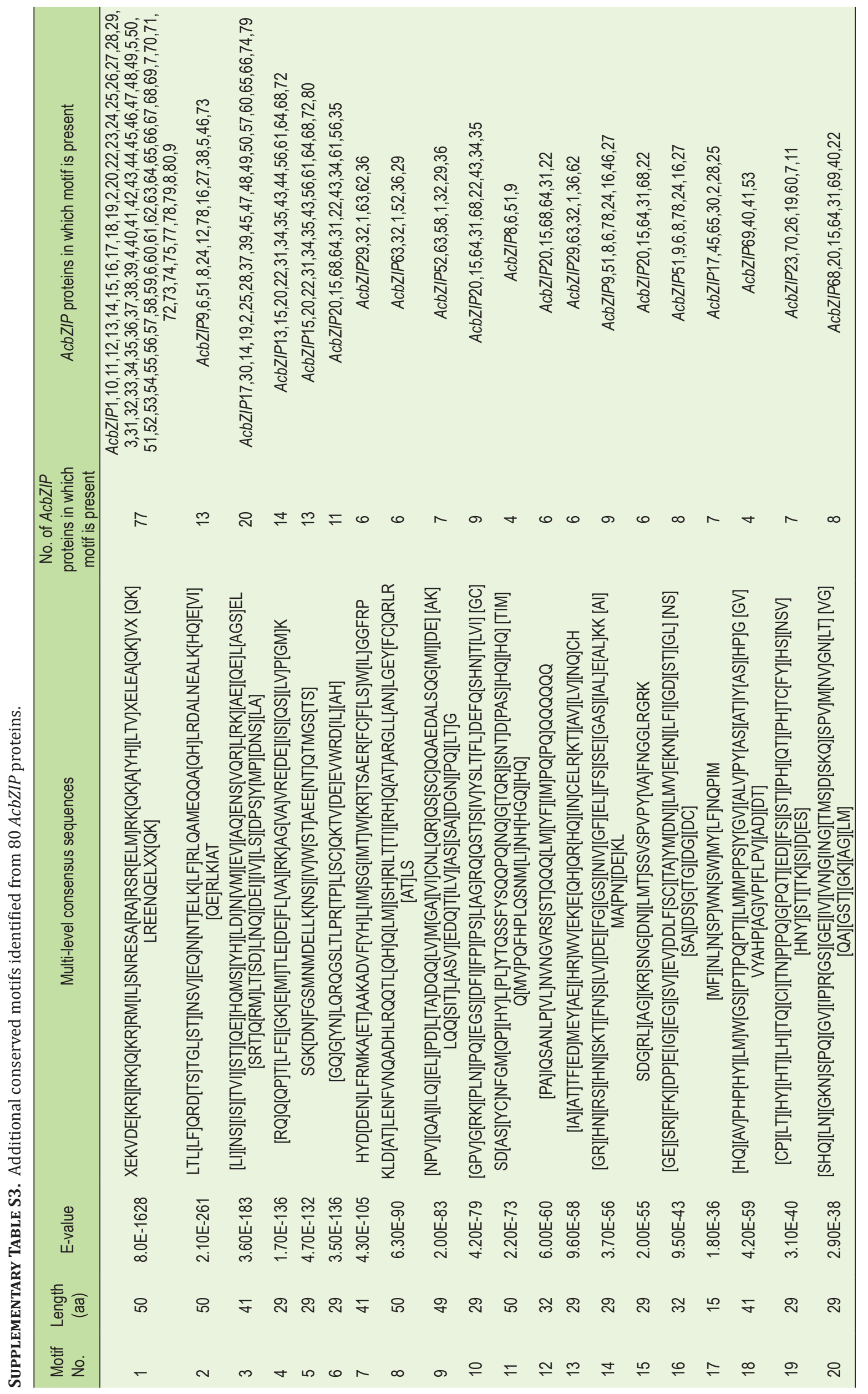


Supplementary TABle S4. Tandem duplication events in the 80 kiwifruit AcbZIP genes.

\begin{tabular}{lcccc}
\hline Cluster number & Gene ID & Chromosome & Start site & End site \\
\hline 1 & AcbZIP19 & 5 & $4,560,105$ & $4,560,695$ \\
& AcbZIP20 & 5 & $4,716,539$ & $4,720,524$ \\
2 & AcbZIP45 & 21 & $12,079,122$ & $12,081,644$ \\
& AcbZIP46 & 21 & $12,153,876$ & $12,161,561$ \\
\hline
\end{tabular}

SUPPLEMENTARY TABLE S5. Synteny blocks of $b Z I P$ genes within kiwifruit genome.

\begin{tabular}{|c|c|c|c|c|c|c|c|c|c|c|}
\hline \multirow{2}{*}{ ID } & \multicolumn{3}{|c|}{ Region1 (kiwifruit) } & \multicolumn{3}{|c|}{ Region2 (kiwifruit) } & \multicolumn{2}{|c|}{ Gene in the synteny region } & \multicolumn{2}{|c|}{ Gene name } \\
\hline & $\mathrm{Chr}$ & Start & Stop & $\mathrm{Chr}$ & Start & Stop & Gene 1 & Gene 2 & Gene 1 & Gene 2 \\
\hline 1 & Chr1 & 2371829 & 2874852 & Chr5 & 17827057 & 18823165 & Achn076181 & Achn296661 & AcbZIP3 & AcbZIP21 \\
\hline 2 & Chr1 & 834573 & 1014187 & Chr9 & 7339414 & 7517854 & Achn094351 & Achn136681 & AcbZIP1 & AcbZIP29 \\
\hline 3 & Chr1 & 1403633 & 1919298 & Chr9 & 4376982 & 4958615 & Achn135561 & Achn201271 & AcbZIP2 & AcbZIP28 \\
\hline 4 & Chr11 & 762760 & 1035549 & Chr1 & 1483731 & 2023713 & Achn025721 & Achn135561 & AcbZIP30 & AcbZIP2 \\
\hline 5 & Chr11 & 623477 & 1086143 & Chr4 & 10548353 & 11146162 & Achn025721 & Achn049201 & AcbZIP30 & AcbZIP17 \\
\hline 6 & Chr11 & 1275804 & 2385657 & Chr4 & 8481738 & 9993279 & Achn026271 & Achn158851 & AcbZIP31 & AcbZIP15 \\
\hline 7 & Chr11 & 403340 & 2555158 & Chr6 & 15484537 & 17821077 & Achn026271 & Achn233651 & AcbZIP31 & AcbZIP22 \\
\hline 8 & Chr11 & 623477 & 1313843 & Chr9 & 4304002 & 5189407 & Achn025721 & Achn201271 & AcbZIP30 & AcbZIP28 \\
\hline 9 & Chr12 & 8294314 & 8672132 & Chr2O & 12545699 & 12722021 & Achn173651 & Achn270881 & AcbZIP35 & - \\
\hline 10 & Chr15 & 578066 & 1197478 & Chr25 & 9930983 & 10438361 & Achn184611 & Achn331511 & AcbZIP41 & AcbZIP53 \\
\hline 11 & Chr2 & 10582131 & 11760758 & Chr27 & 7396311 & 8589526 & Achn293811 & Achn338531 & AcbZIP7 & AcbZIP60 \\
\hline 12 & Chr21 & 11809820 & 12570028 & Chr1 & 1348842 & 1980234 & Achn015171 & Achn135561 & AcbZIP45 & $A c b Z I P 2$ \\
\hline 13 & Chr21 & 11210647 & 12081644 & Chr11 & 876192 & 1370339 & Achn015171 & Achn025721 & AcbZIP45 & AcbZIP30 \\
\hline 14 & Chr21 & 7052064 & 7524912 & Chr4 & 5049812 & 5247304 & Achn290761 & Achn305211 & AcbZIP44 & AcbZIP13 \\
\hline 15 & Chr22 & 11094441 & 11880883 & Chr24 & 747029 & 1302588 & Achn059341 & Achn103311 & AcbZIP47 & AcbZIP50 \\
\hline 16 & Chr23 & 19721715 & 20666117 & Chr13 & 221213 & 967308 & Achn024761 & Achn229321 & AcbZIP49 & AcbZIP37 \\
\hline 17 & Chr23 & 16583963 & 16786550 & Chr13 & 7057100 & 7314165 & Achn191271 & Achn214181 & - & AcbZIP38 \\
\hline 18 & Chr24 & 13028939 & 13330770 & Chr2 & 2127381 & 2353519 & Achn147981 & Achn251071 & AcbZIP51 & AcbZIP6 \\
\hline 19 & Chr26 & 4834952 & 5604687 & Chr25 & 11995337 & 12634770 & Achn084391 & Achn096361 & AcbZIP55 & AcbZIP54 \\
\hline 20 & Chr26 & 11450709 & 12729232 & Chr28 & 10716428 & 12066768 & Achn068551 & Achn200201 & AcbZIP56 & AcbZIP61 \\
\hline 21 & Chr27 & 3096850 & 3470623 & Chr25 & 7098369 & 7359352 & Achn170511 & Achn251821 & - & AcbZIP52 \\
\hline 22 & Chr27 & 4437680 & 4858600 & Chr5 & 48486 & 565179 & Achn210621 & Achn254431 & - & AcbZIP18 \\
\hline 23 & Chr3 & 14611063 & 16114725 & Chr2 & 11123156 & 12530279 & Achn057151 & Achn293811 & AcbZIP11 & AcbZIP7 \\
\hline 24 & Chr3 & 10451976 & 11695808 & Chr2 & 1965465 & 2988546 & Achn062651 & Achn251071 & AcbZIP9 & AcbZIP6 \\
\hline 25 & Chr3 & 11015733 & 11785438 & Chr23 & 16180360 & 16640371 & Achn062651 & Achn191271 & AcbZIP9 & - \\
\hline 26 & Chr3 & 10155487 & 11206639 & Chr24 & 12943189 & 13691997 & Achn062651 & Achn147981 & AcbZIP9 & AcbZIP51 \\
\hline 27 & Chr3 & 1518906 & 2233352 & Chr24 & 11679371 & 13127713 & Achn054841 & Achn147981 & AcbZIP8 & AcbZIP51 \\
\hline 28 & Chr3 & 14364874 & 15332373 & Chr27 & 7396311 & 8589526 & Achn057151 & Achn338531 & AcbZIP11 & AcbZIP60 \\
\hline 29 & Chr3 & 14611063 & 15646650 & Chr5 & 4482927 & 5847398 & Achn057151 & Achn062291 & AcbZIP11 & AcbZIP19 \\
\hline 30 & Chr4 & 10556611 & 10932260 & Chr1 & 1062750 & 1695481 & Achn049201 & Achn135561 & AcbZIP17 & AcbZIP2 \\
\hline 31 & Chr4 & 10501611 & 10902278 & Chr21 & 12122999 & 12521802 & Achn049341 & Achn230471 & AcbZIP16 & AcbZIP46 \\
\hline 32 & Chr4 & 3205541 & 4900887 & Chr21 & 6467739 & 7424965 & Achn121041 & Achn290821 & AcbZIP12 & - \\
\hline 33 & Chr4 & 10548353 & 10932260 & Chr9 & 4545207 & 5189407 & Achn049201 & Achn201271 & AcbZIP17 & AcbZIP28 \\
\hline 34 & Chr5 & 3571004 & 4602360 & Chr2 & 10582131 & 11461478 & Achn062291 & Achn293811 & AcbZIP19 & AcbZIP7 \\
\hline 35 & Chr5 & 2945099 & 4975044 & Chr27 & 6954897 & 8589526 & Achn062291 & Achn338531 & AcbZIP19 & AcbZIP60 \\
\hline 36 & Chr7 & 1303601 & 2216331 & Chr11 & 863151 & 1857439 & Achn006801 & Achn025721 & AcbZIP25 & AcbZIP30 \\
\hline 37 & Chr8 & 11204864 & 13156651 & Chr1 & 13163591 & 14648527 & Achn237931 & Achn327661 & AcbZIP27 & - \\
\hline
\end{tabular}


found that belong to two tandem duplication event regions on chromosome 5 (one cluster), 21 (one cluster) (Supplementary Table S4). In addition, 37 segregation duplication events were identified on kiwifruit chromosomes $1,2,4,5,6$, 9, 11, 13, 20, 21, 23, 24, 25, 27, 28 (Figure 3; Supplementary Table S5).
In order to clarify the origin of kiwifruit bZIP TFs and the evolutionary relationship between the kiwifruit and Arabidopsis, we also performed a comparative bZIP gene families synteny map of the kiwifruit and Arabidopsis genomes. The corresponding orthologs of 29 kiwifruit AcbZIP genes and 29 AcbZIP Arabidopsis were identified (Figure 4; Supplementary Table S6).

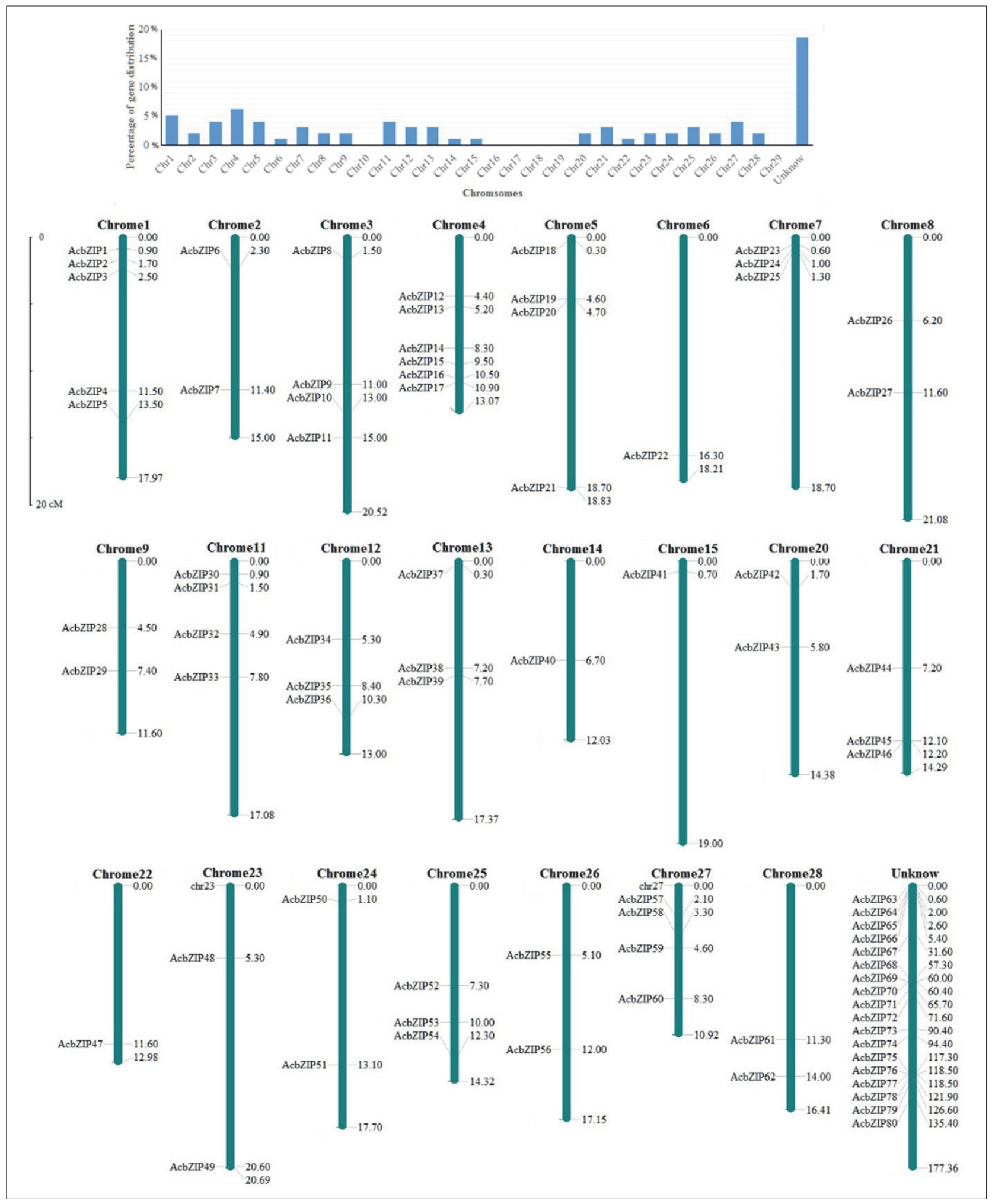

FIGURE S3. The distribution of AcbZIP genes in kiwifruit chromosomes. The number of bZIP genes is shown at the top in each chromosome. Eighteen of the 80 AcbZIP could not be mapped to any chromosome and are not shown. 


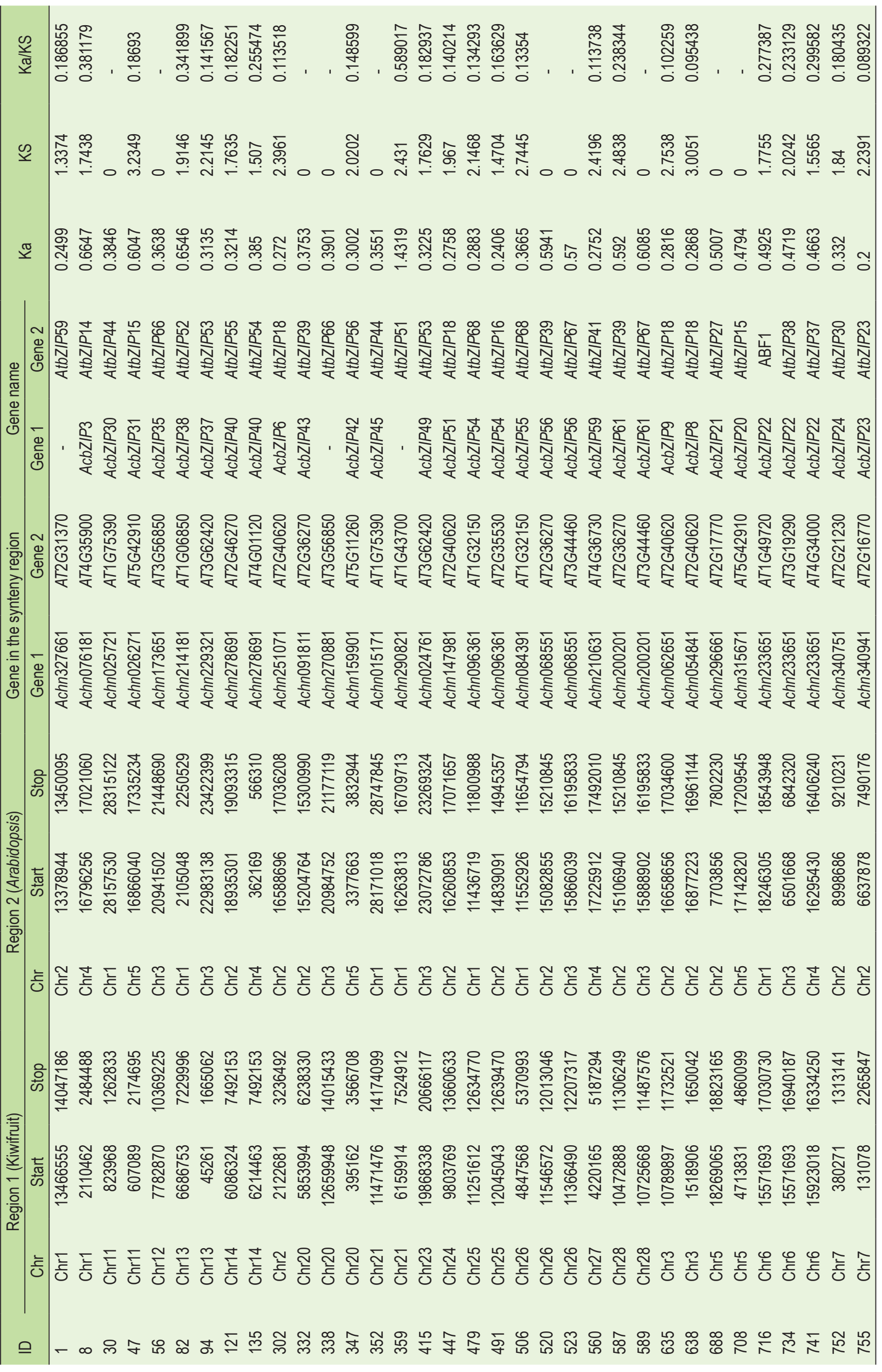




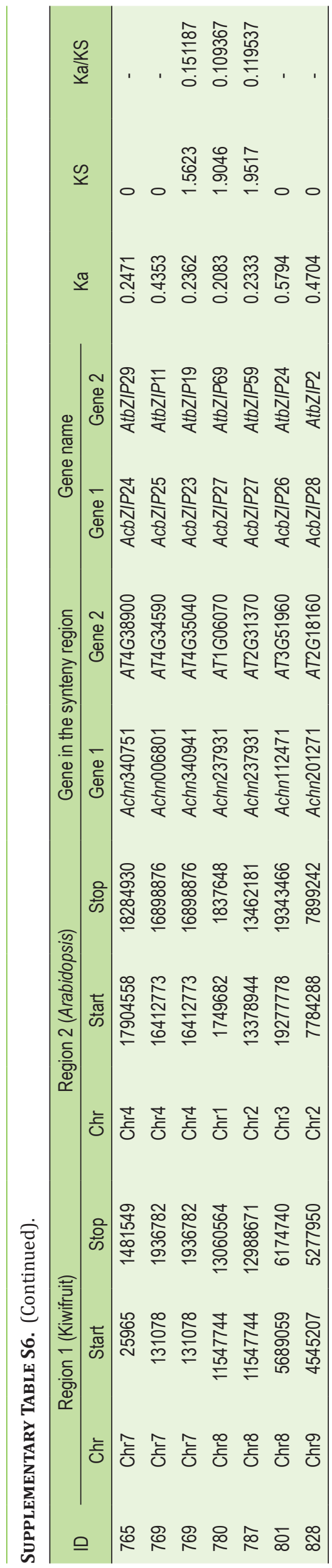

\section{Expression patterns of kiwifruit group A AcbZIP genes} in different organs

To identify potential functions of the AcbZIP genes, semi-quantitative RT-PCR was carried out to assess their expression pattern in five different tissue organs including apical buds, young leaves, stems, flower buds, and fruits. Some studies have indicated that Group A bZIP genes involved in abiotic stress regulation and ABA signal transduction in seeds (Jakoby et al., 2002). Therefore, 16 Group A bZIP kiwifruit genes were selected to analyze the expression patterns by semi-quantitative RT-PCR. The results indicated that the 16 selected AcbZIP genes were expressed in all organs, and each AcbZIP gene showed a different expression level among the different organs (Supplementary Figure S4). Most of the genes showed a relatively high expression in apical buds, flower buds, and fruits compared to young leaves and stems.

Expression profiles of kiwifruit group A AcbZIP genes in response to Psa, salt, drought and hormone treatments

To further identify potential roles for kiwifruit AcbZIP genes in response to Psa, salt, drought and hormone treatments, semi-quantitative RT-PCR was used to analyze the expression profiles of 16 Group A bZIP genes in response to Psa, salt, drought and hormone treatments at different times (Supplementary Figures S5 and S6). The results showed that diverse expression patterns were found and some of the genes were up-regulated, while others were down-regulated. As shown in Figure S2, several genes (such as AcbZIP13, AcbZIP15, AcbZIP20, AcbZIP22) showed decreased $72 \mathrm{~h}$ post Psa treatment, but then increased at $120 \mathrm{~h}$ after Psa treatment. AcbZIP13, AcbZIP15, AcbZIP20, AcbZIP22 and AcbZIP64 showed an obvious increase in expression from $96 \mathrm{~h}$ post-treatment with drought, while the expression decreased after R48 h treatment. As shown in Figure S3,

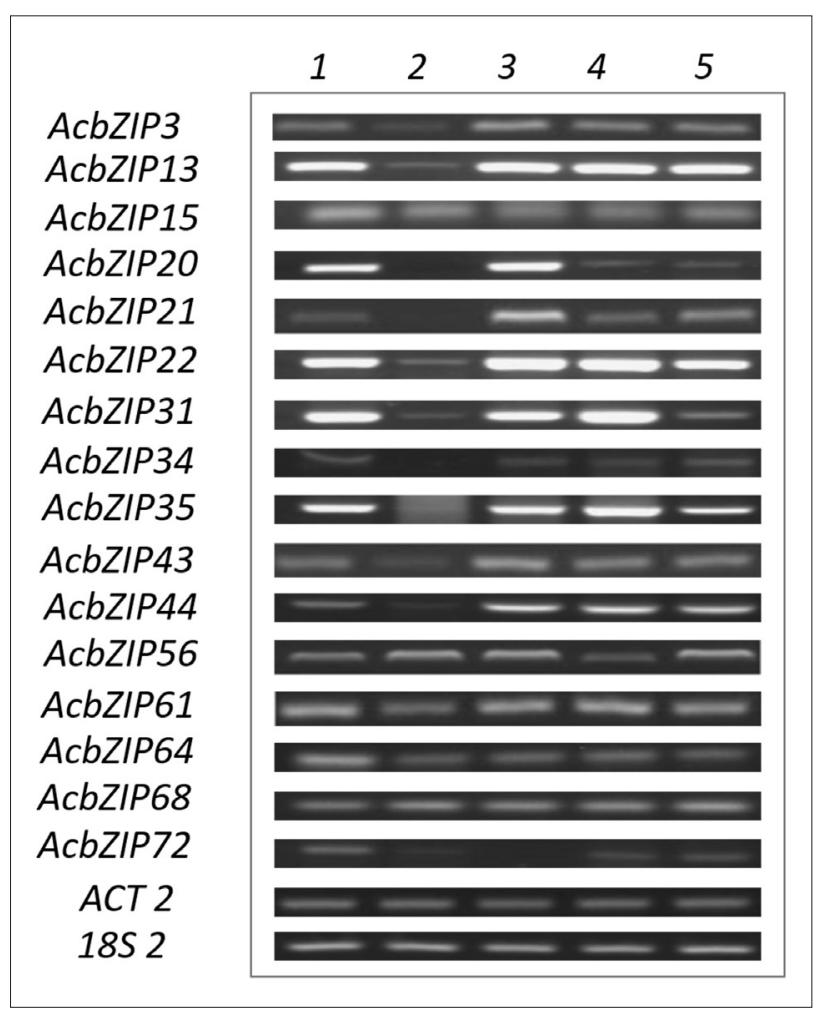

FigURE S4. Expression analysis of Group A AcbZIP genes in five organs. Organs are indicated as follows: 1 - young leaves; 2 - stems; 3 - apical buds; 4 - flower buds; 5 - fruits. 


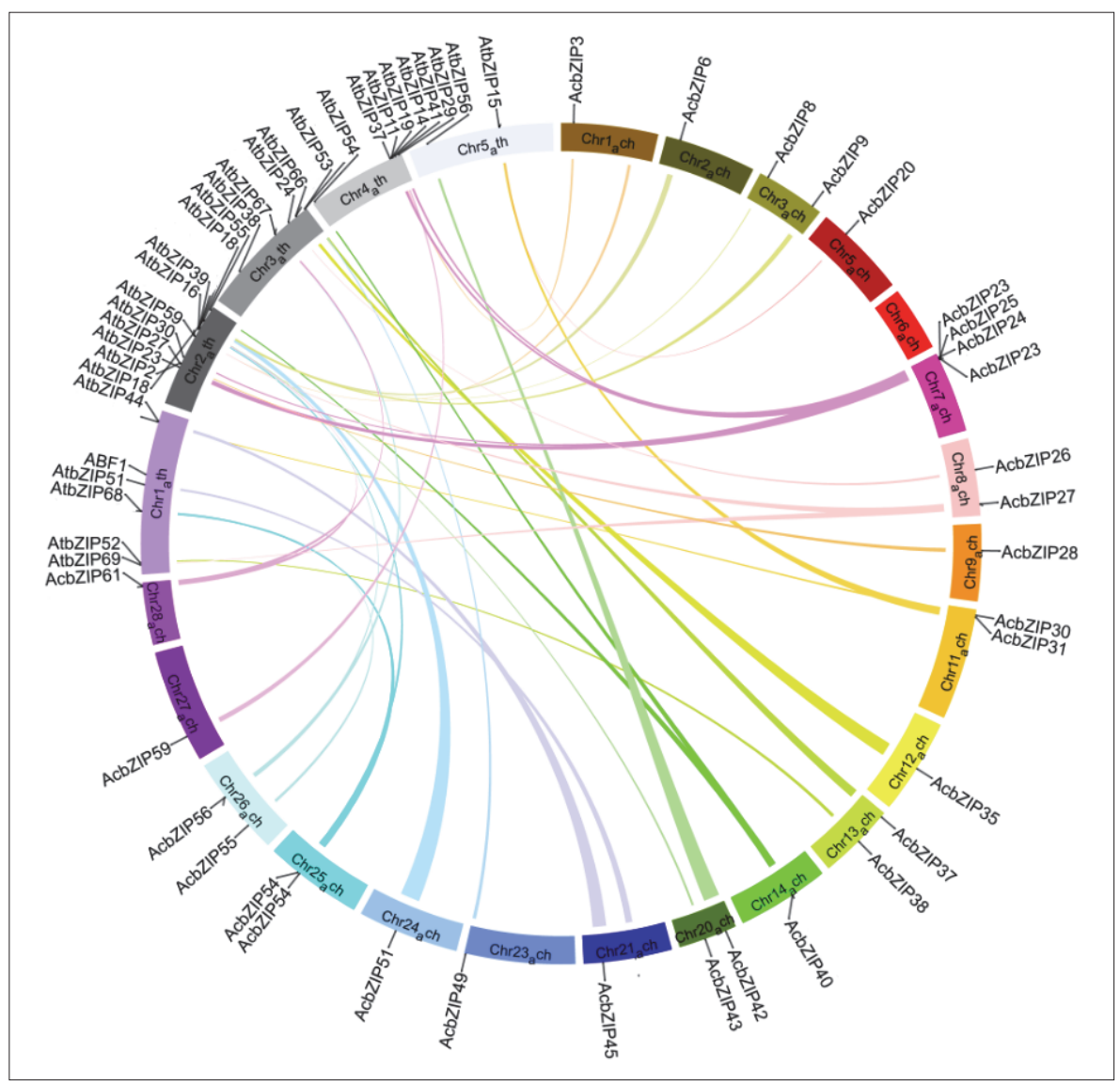

FIGURE 4. Synteny analysis of bZIP genes between kiwifruit and Arabidopsis. Kiwifruit and Arabidopsis bZIP genes are indicated by vertical black lines. Colored lines connect the syntenic regions between kiwifruit and Arabidopsis bZIP genes.

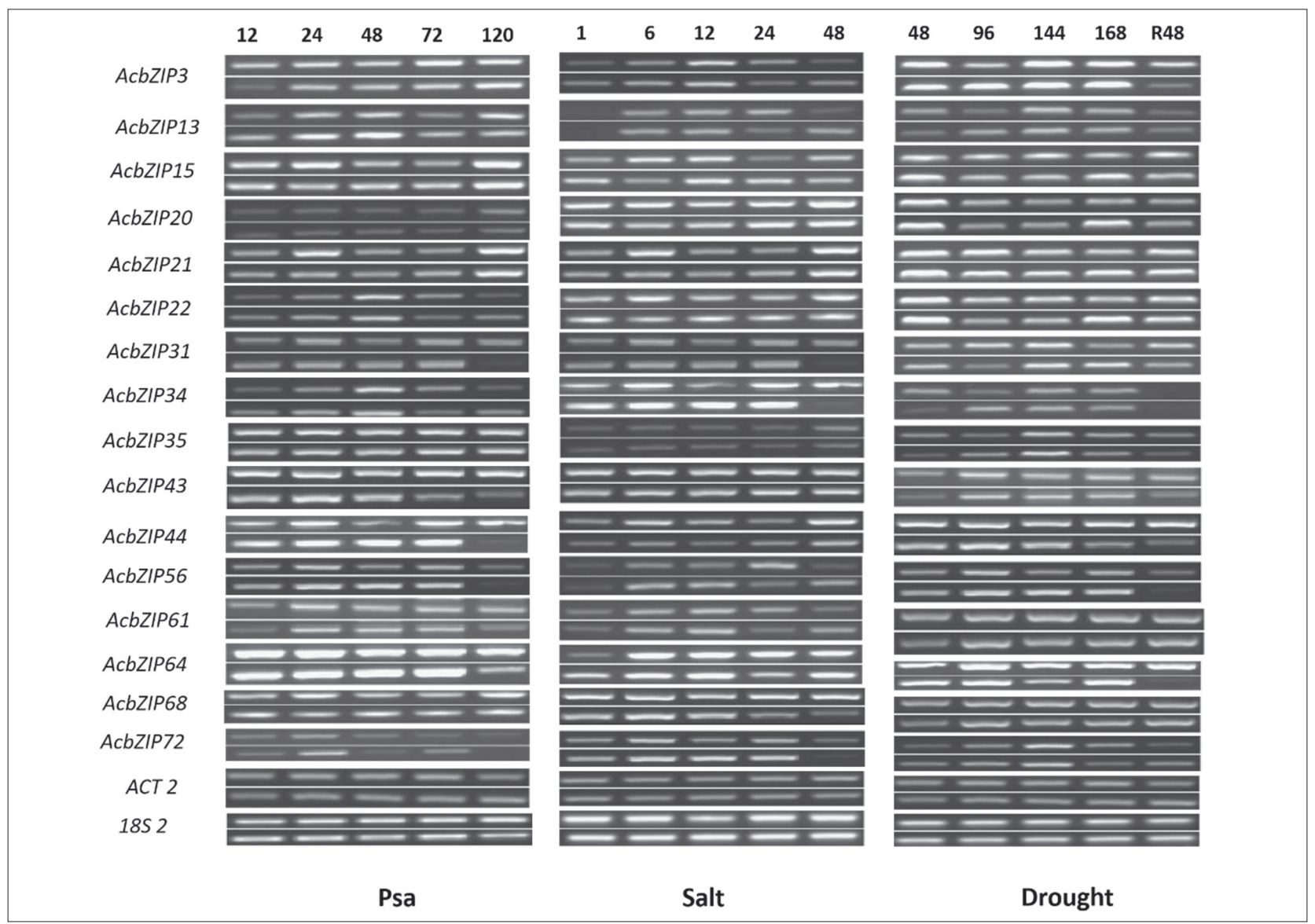

FIGURE S5. Expression levels of Group A AcbZIP genes following Psa, salt, and drought treatments by semi-quantitative RTPCR. 
AcbZIP13, AcbZIP15, AcbZIP22 and AcbZIP31 showed similar expression levels and no obvious increased expression at different time points following the hormone treatments. To verify the efficacy of the semi-quantitative RT-PCR analyses, the expression of seven selected AcbZIP genes (AcbZIP13, AcbZIP15, AcbZIP20, AcbZIP22, AcbZIP31, AcbZIP64 and AcbZIP68) following Psa, salt, drought and hormone treatments were analyzed using quantitative real-time PCR (Figure 5).

\section{Discussion}

In this study, we performed a genome-wide identification of kiwifruit bZIP genes and analyze their evolutionary histories and expression pattern in different kiwifruit organs and biotic and abiotic stresses. These results may provide some research resource to further analyze the function of AcbZIP genes in kiwifruit.
In the present research, we identified 80 AcbZIP genes according to the core bZIP domain. Multiple sequence alignment showed that 80 of the AcbZIP genes contain a highly conserved sequence $\mathrm{N}-\mathrm{x} 7-\mathrm{R} / \mathrm{K}-\mathrm{x} 9$ motif and a leucine zipper motif. These results have also been found in the grape, apple bZIP TFs (Zhao et al., 2016; Gao et al., 2014). Genomic comparison could provide an efficient method for transferring genomic information within one taxon (Peterson et al., 2012). Arabidopsis is considered to be the best model plant species for the phylogenetic relationship of bZIP TFs (Zhao et al., 2016; Gao et al., 2014). In this study, an unrooted neighbor-joining (NJ) tree was constructed using a multiple alignment of full-length protein sequence. The kiwifruit AcbZIP TFs is divided into ten groups (A, B, C, D, E, F, G, H, I, and S) depending on the characteristics of bZIP sequence that including highly conserved sequence N-x7-R/K-x9 motif and

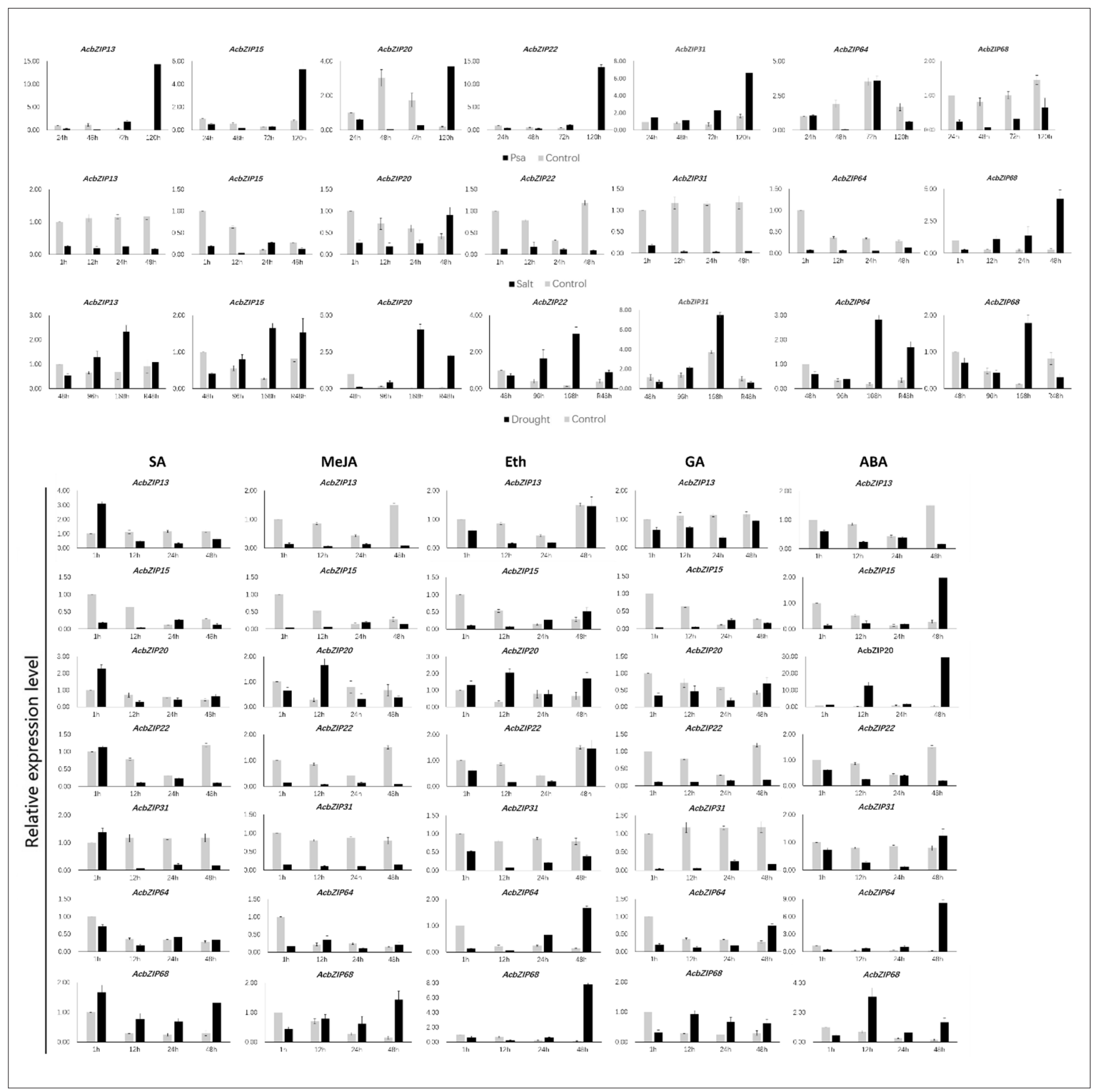

Figure 5. Expression levels of Group A AcbZIP genes following Psa, salt, and drought, and different hormone treatments (salicylic acid-SA; Amethyl jasmonic acid-MeJA; Ethylene-Eth; gibberellins-GA; abscisic acid-ABA) treatments by quantitative real-time RT-PCR. The error bars were calculated by three biological and technical replicates. 


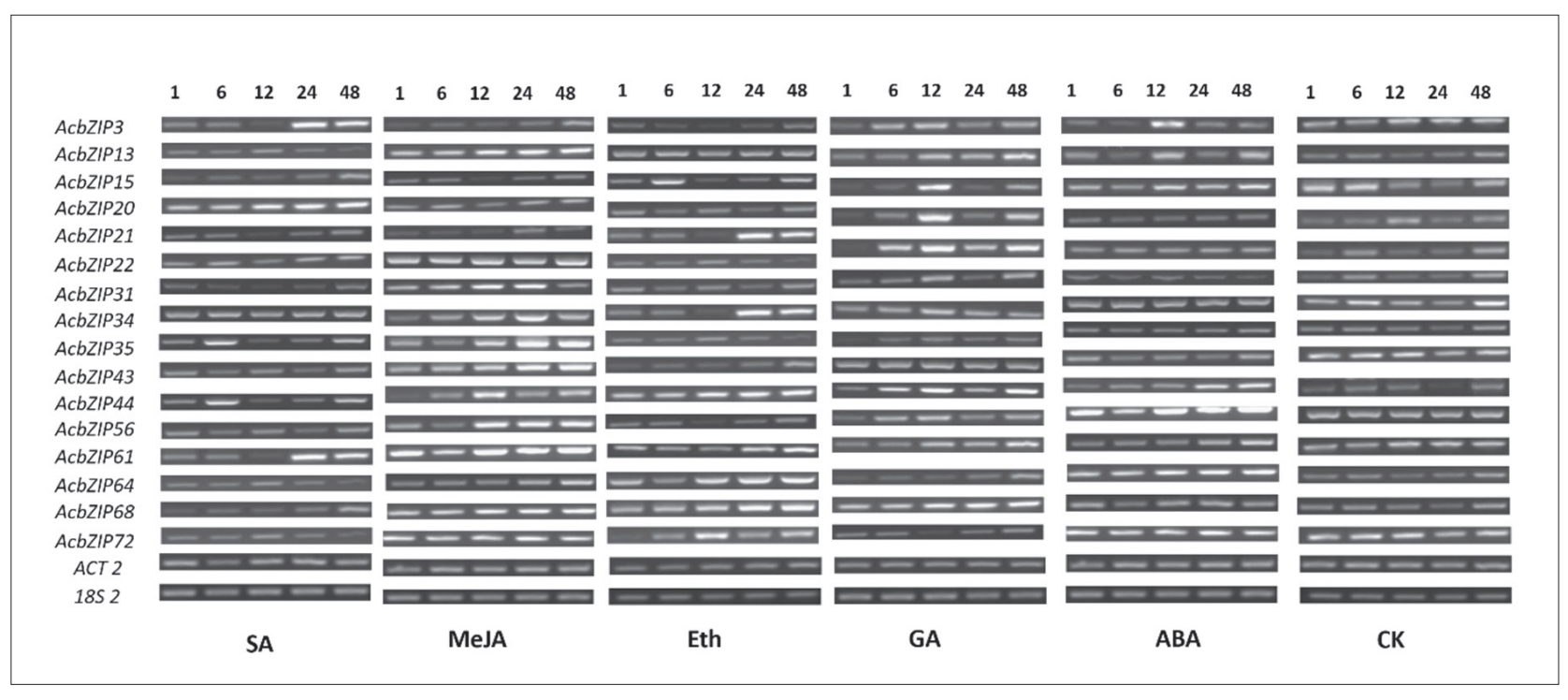

FIGURE S6. Expression levels of Group A AcbZIP genes with different hormone treatments (SA - salicylic acid; MeJA - methyl jasmonic acid; Eth - ethylene; GA - gibberellins; ABA - abscisic acid) by semi-quantitative RT-PCR.

a leucine zipper motif, which was in accordance with Arabidopsis, and sorghum (Wang et al., 2011; Jakoby et al., 2002). In addition, 13 groups also were present in some plants, such as Arabidopsis, rice, black cottonwood, apple and grape (Zhao et al., 2016; Gao et al., 2014; Corrêa et al., 2008). In this study, we found that kiwifruit has a larger number of bZIP genes than other plants, such as cassava (77) (Hu et al., 2016), Arabidopsis (75) (Jakoby et al., 2002), cucumber (64) (Baloulu et al., 2014), and grape (55) (Gao et al., 2014), while compared with rice (89) (Nijhawan et al., 2008), sorghum (88) (Wang et al., 2011), maize (125) (Wei et al., 2012), castor bean (100) (Jin et al., 2014), apple (112 or 144) (Li et al., 2016; Zhao et al., 2016), Chinese cabbage (136) (Bai et al., 2016), the kiwifruit AcbZIP genes are few. The reason may be related to the size of genome. For example, the genomic size of several plants in this order: kiwifruit (616.1 Mb) (Huang et al., 2013), grape (490 Mb) (Gao et al., 2014), cucumber (367 Mb) (Huang et al., 2009), Arabidopsis (119 Mb) (International Rice Genome Sequencing Project, 2005). However, the number of TFs and the genome size are not necessarily correlated (Song et al., 2016). For example, the genome size of rice (389 Mb) (International Rice Genome Sequencing Project) is smaller than kiwifruit, but the number of bZIP are higher than kiwifruit.

Previous studies indicated that exon/intron structure can also provide crucial information to analyze the phylogenic relationships for a gene family (Hu et al., 2015). And exon/ intron also play important roles in the evolution of multiple gene families (Zhang et al., 2012). In this study, we analyzed the exon/intron of the 80 AcbZIP genes to help us further understand the evolution. Among 80 AcbZIP genes, the number of introns ranged from 0 to 12 . However, most studies showed that some bZIP TF families had no introns, such as bZIP TFs in apple, grape, rice and sorghum (Zhao et al., 2016; Gao et al., 2014; Wang et al., 2011; Nijhawan et al., 2008). In general, introns of the same group showed similar conserved positions and phases. This is similar with VvbZIP in grape and MdbZIP in apple (Zhao et al., 2016; Gao et al., 2014). Additionally, the intron/exon loss/gain were found within the same AcbZIP gene. For example, AcbZIP5, AcbZIP38, AcbZIP16, AcbZIP24, AcbZIP78, AcbZIP12, AcbZIP27, AcbZIP6,
AcbZIP8, AcbZIP9, AcbZIP51 have three or four introns, while AcbZIP46 genes in the same group I have only one intron. This intron/exon loss or gain may be caused by the rearrangement and fusions of different chromosome fragments (Guo et al., 2014). Conserved motifs could also provide further confirmation of the evolutionary relationship among the kiwifruit AcbZIP genes. Phylogenetic relationship results indicated that the same group generally contains the similar number of amino acids and motif composition, which may show that the molecular structures were highly conserved during evolution in the same group (Figure 3C). Similar patterns have also been reported in grape and apple (Zhao et al., 2016; Gao et al., 2014).

This has been made possible to reconstruct the evolutionary history of a gene by comparing the sequences of all genes among genomes from different taxa or within each genome (Koonin, 2005). Previous researches indicated that Arabidopsis is considered to be the best model plant species of bZIP TFs studies (Zhao et al., 2016; Gao et al., 2014). Thus, the origin and evolutionary history of the AcbZIP genes were analyzed by comparative synteny map between the kiwifruit and Arabidopsis genomes (Figure 5). According to this syntenic map, 29 AcbZIP genes have 29 Arabidopsis corresponding orthologs, suggesting that the expansion might have occurred before the divergence of kiwifruit and Arabidopsis. Of these, eight pairs revealed to be single kiwifruit-to-Arabidopsis pairs (Supplementary Table S3), indicating that these AcbZIP genes and their Arabidopsis counterparts share a common ancestor (Gao et al., 2014). From these homologs results, we may be obtaining the function information of some kiwifruit AcbZIP genes. Other gene combinations showed a different syntenic relationship, with eight gene-pairs that one single kiwifruit gene corresponded to multiple Arabidopsis genes, seven gene-pairs that kiwifruit segmental duplications corresponded to single Arabidopsis gene (Supplementary Table S3). In addition, we found that more AcbZIP genes could not be mapped into any synteny blocks, but it cannot be concluded that these genes did not share a common ancestor with Arabidopsis bZIP genes. The reasons may be explained by the fact that after the speciation of kiwifruit and Arabidopsis, their genomes may have undergone multiple rounds of sig- 
nificant chromosomal rearrangement and fusions, followed by selective gene loss, which can severely obscure chromosomal syntenies (Zhao et al., 2016; Gao et al., 2014; Paterson et al., 2012). Moreover, the Ka, Ks, and $\mathrm{Ka} / \mathrm{Ks}$ of the syntenic orthologous gene-pairs showed $\mathrm{Ka} / \mathrm{Ks}$ ration $<1$ that these genes may underwent a strong Darwinian purifying positive selection; based on these results we also inferred that some of the kiwifruit genes shared a common ancestor with their Arabidopsis bZIP counterparts (Zhao et al., 2016).

The AcbZIP genes were located to the 23 kiwifruit chromosomes based on the chromosome annotation of the kiwifruit genome, indicating that not all 29 chromosomes contain an AcbZIP gene, and chromosomes 10, 16, 17, 18, 19, and 29 have no AcbZIP genes. The largest numbers of $A c b$ ZIP genes are chromosomes 4, eighteen AcbZIP genes were not assigned on any of the chromosomes; these results were also found in grape MdbZIP genes (Li et al., 2016; Zhao et al., 2016). Tandem and segmental duplicated events of genome duplication play an important role in generating new duplicated genes and evolution of organisms (Song et al., 2016; Zhao et al., 2016; Gao et al., 2014). Whole-genome duplication $(\gamma, \beta, \alpha)$ followed by gene loss is regarded as the major evolutionary force (Huang et al., 2013), and often lead to gene family expansion (Cannon et al., 2004). Kiwifruit has undergone an ancient hexaploidization event $(\gamma)$ shared by core eudicots and two more recent whole-genome duplication events (Huang et al., 2013). Furthermore, kiwifruit also has undergone large gene duplication in its evolution process and 10,581 duplicated genes have been found in the kiwifruit genome (Huang et al., 2013). In this study, we only identified two pairs of tandem duplications (AcbZIP19/ AcbZIP20; AcbZIP45/AcbZIP46) on kiwifruit chromosomes 5 and 21, respectively, indicating a few contribution of tandem duplication to AcbZIP gene family expansion. Same results were found in grape and sorghum, including two and three tandem duplication event regions, respectively (Gao et al., 2014; Wang et al., 2011). However, 37 AcbZIP genes were associated with segmental duplication events, indicating that segmental duplication events could be regarded as a major mechanism to drive the expansion of kiwifruit AcbZIP gene families. As a whole, tandem and segmental duplications may play important roles in the expansion and evolution of the AcbZIP gene family in kiwifruit.

From most previous researches we know that bZIP genes play essential roles in response to various abiotic and biotic stress for many plants. Compared with other plant species, the responses of kiwifruit bZIP genes to abiotic and biotic stress, such as salt, drought, pathology resistance, and hormone, have not been studied. In addition, the expression patterns of bZIP genes also have not been studied in kiwifruit different tissues. The function of bZIP genes had been studied in lots of plant species, especially in Arabidopsis, rice and tomato. For example, overexpression of AlAREB1 plays a role in response to abiotic stress in tomato (Yáñez et al., 2009). AREB1 could enhance drought stress tolerance in $A$. thaliana (Fujita et al., 2005). ABF3 was reported to reduce transpiration and enhance drought tolerance (Kang et al., 2002). Drought and salt are major abiotic stresses affecting growth of plants and result in severe yield losses for economic crops (Li et al., 2013). bZIP TF gene could be induced by drought and salt in some plants, such as Arabidopsis, grape, tomato. For example, ABP9 showed enhanced drought stresses (Zhang et al., 2008), VvbZIP23 was induced by drought and cold stress (Tak and Mhatre, 2013), and StABF1 was reported to enhance drought tolerance (García et al., 2012). In the present study, we analyzed the AcbZIP genes expression patterns in response to drought and salt abiotic stresses. AcbZIP13, AcbZIP15, AcbZIP20, AcbZIP22, AcbZIP31, AcbZIP64 and AcbZIP68 showed a peak of expression at $168 \mathrm{~h}$ after drought treatment, indicating that a certain response time is needed for bZIP genes to response to drought stress, similar results were found in WRKY genes (Guo et al., 2014). The reasons may be that the temporal and spatial diversification of bZIP gene expression is widespread. Similar results were also found in Psa biotic stress, including AcbZIP13, AcbZIP15, AcbZIP20, AcbZIP22, AcbZIP31, AcbZIP64 showed down-regulation during early infection, and up-regulated during a later time. Some plant hormones, including Eth, SA, MeJA, ABA and GA have been reported to play important roles in the growth and development of plants, and involved in the different biotic and abiotic stress responses in plants. For example, Eth, SA and GA have key roles in biotic stress signaling upon pathogen infection; ABA is involved in response to pathogen infection, water-deficit, cold and osmotic stress (Zhao et al., 2016; Gao et al., 2014; Bari et al., 2009). Our studies show that the AcbZIP genes have a variety of response patterns after various hormone treatments, indicating that they may be induced by the hormones.

\section{Conclusions}

In conclusion, we performed the first genome-wide analysis of 80 kiwifruit AcbZIP TF family. Synteny analyses showed that tandem and segmental duplications mainly have contributed to the expansion of the kiwifruit AcbZIP gene family. Phylogenetic and gene structure analyses revealed the classification and evolution relationship of 80 AcbZIP genes. Some AcbZIP genes expression indicated that they play an important role in response to various biotic and abiotic stresses. These results may provide some information for further gene clone and functional research in kiwifruit.

\section{Acknowledgments}

This work was supported by the earmarked fund for China Postdoctoral Science Foundation (2015M582712), Postdoctoral Science Foundation of Shaanxi Province (2016BSHYDZZ07), Science and Technology Research and Development Program of Shaanxi Province (2015KTZDNY02-03-01, 2016KJXX-58). We thank AJE (https://www.aje. $\mathrm{com} /$ ) for editing this manuscript.

\section{References}

Bai, Y., Zhu, W., Hu, X., Sun, C., Li, Y., Wang, D., Wang, Q., Pei, G., Zhang, Y., Guo, A., Zhao, H., Lu, H., Mu, X., Hu, J., Zhou, X., and Xie, C.G. (2016). Genome-wide analysis of the bZIP gene family identifies two ABI5like bZIP transcription factors, BrABI5a and BrABI5b, as positive modulators of ABA signalling in Chinese cabbage. PLoS ONE 11(7), e0158966. https://doi.org/10.1371/journal.pone.0158966.

Baloglu, M.C., Eldem, V., Hajyzadeh, M., and Unver, T. (2014). Genomewide analysis of the bZIP transcription factors in cucumber. PLoS ONE 9, e96014. https://doi.org/10.1371/journal.pone.0096014.

Bari, R., and Jones, J.D. (2009). Role of plant hormones in plant defense responses. Plant Mol. Biol. 69(4), 473-488. https://doi. org/10.1007/s11103-008-9435-0.

Cannon, S.B., Mitra, A., Baumgarten, A., Young, N.D., and May, G. (2004). The roles of segmental and tandem gene duplication in the evolution of large gene families in Arabidopsis thaliana. BMC Plant Biol. 4, 10. https://doi.org/10.1186/1471-2229-4-10.

Corrêa, L.G., Riaño-Pachón, D.M., Schrago, C.G., dos Santos, R.V., Mueller-Roeber, B., and Vincentz, M. (2008). The role of bZIP 
transcription factors in green plant evolution: adaptive features emerging from four founder genes. PLoS ONE 3, e2944. https://doi. org/10.1371/journal.pone.0002944.

Ferradás, Y., Rey, L., Martinez, O., Rey, M., and González, M.V. (2016). Identification and validation of reference genes for accurate normalization of real-time quantitative PCR data in kiwifruit Plant Physiol. Biochem. 102, 27-36. https://doi.org/ 10.1016/j. plaphy.2016.02.011.

Fujita, Y., Fujita, M., Satoh, R., Maruyama, K., Parvez, M.M., Seki, M., et al. (2005). AREB1 is a transcription activator of novel ABREdependent ABA signaling that enhances drought stress tolerance in Arabidopsis. Plant Cell 17, 3470-3488. https://doi.org/10.1105/ tpc.105.035659.

Gao, M., Zhang, H.J., Guo, C.L., Cheng, C.X., Guo, R.R., Mao, L.Y., Fei, Z.J., and Wang, X.P. (2014). Evolutionary and expression analyses of basic zipper transcription factors in the highly homozygous model grape PN40024 (Vitis vinifera L.). Plant Mol. Biol. Rep. 32, 1085-1102. https://doi.org/10.1007/s11105-014-0723-3.

García, M.N.M., Giammaria, V., Grandellis, C., Téllez-Iñón, M.T., Ulloa, R.M., and Capiati, D.A. (2012). Characterization of StABF1, a stressresponsive bZIP transcription factor from Solanum tuberosum L. that is phosphorylated by StCDPK2 in vitro. Planta 235(4), 761-778. https://doi.org/10.1007/s00425-011-1540-7.

Guan, Y., Ren, H., Xie, H., Ma, Z., and Chen, F. (2009). Identification and characterization of bZIP-type transcription factors involved in carrot (Daucus carota L.) somatic embryo genesis. Plant J. 60, 207-217. https://doi.org/10.1111/j.1365-313X.2009.03948.x.

Guo, C., Guo, R., Xu, X., Gao, M., Li, X., Song, J., Zheng, Y., and Wang, X. (2014). Evolution and expression analysis of the grape (Vitis vinifera L.) WRKY gene family. J. Exp. Bot. 65(6), 1513-1528. https://doi. org/10.1093/jxb/eru007.

Hu, B., Jin, J., Guo, A.Y., Zhang, H., Luo, J., and Gao, G. (2015). GSDS 2.0: an upgraded gene feature visualization server. Bioinformatics 31(8), 1296-1297. https://doi.org/10.1093/bioinformatics/btu817.

Hu, W., Yang, H., Yan, Y., Wei, Y., Tie, W., Ding, Z., Zuo, J., Peng, M., and Li, K. (2016). Genome-wide characterization and analysis of bZIP transcription factor gene family related to abiotic stress in cassava. Sci. Rep. 6, 22783. https://doi.org/10.1038/srep22783.

Huang, C.J., Zhou, J.H., Jie, Y.C., Xing, H.C., Zhong, Y.L, She, W., Wei, G., Yu, W.L., and Ma, Y.S. (2016). A ramie (Boehmeria nivea) bZIP transcription factor BnbZIP3 positively regulates drought, salinity and heavy metal tolerance. Mol. Breeding 36, 120. https://doi. org/10.1007/s11032-016-0470-2.

Huang, H.W., and Ferguson, A.R. (2007). Actinidia in China: natural diversity, phylogeographical evolution, interspecific gene flow and kiwifruit cultivar improvement. Acta Hortic. 753, 31-40. https://doi. org/10.17660/ActaHortic.2007.753.1.

Huang, S., Ding, J., Deng, D., Tang, W., Sun, H., Liu, D., Zhang, L., Niu, X., Zhang, X., Meng, M., Yu, J., Liu, J., Han, Y., Shi, W., Zhang, D., Cao, S., Wei, Z., Cui, Y., Xia, Y., Zeng, H., Bao, K., Lin, L., Min, Y., Zhang, H., Miao, M., Tang, X., Zhu, Y., Sui, Y., Li, G., Sun, H., Yue, J., Sun, J., Liu, F., Zhou, L., Lei, L., Zheng, X., Liu, M., Huang, L., Song, J., Xu, C., Li, J., Ye, K., Zhong, S., Lu, B.R., He, G., Xiao, F., Wang, H.L., Zheng, H., Fei, Z., and Liu, Y. (2013). Draft genome of the kiwifruit Actinidia chinensis. Nat. Commun. 4, 2640. https://doi.org/10.1038/ncomms3640.

Huang, S., Li, R., Zhang, Z., Li, L., Gu, X., Fan, W., Lucas, W.J., Wang, X., Xie, B., Ni, P., Ren, Y., Zhu, H., Li, J., Lin, K., Jin, W., Fei, Z., Li, G., Staub, J., Kilian, A., van der Vossen, E.A., Wu, Y., Guo, J., He, J., Jia, Z., Ren, Y., Tian, G., Lu, Y., Ruan, J., Qian, W., Wang, M., Huang, Q., Li, B., Xuan, Z., Cao, J., Asan, Wu, Z., Zhang, J., Cai, Q., Bai, Y., Zhao, B., Han, Y., Li, Y., Li, X., Wang, S., Shi, Q., Liu, S, Cho, W.K., Kim, J.Y., Xu, Y., Heller-Uszynska, K., Miao, H., Cheng, Z., Zhang, S., Wu, J., Yang, Y., Kang, H., Li, M., Liang, H., Ren, X., Shi, Z., Wen, M., Jian, M., Yang, H., Zhang, G., Yang, Z., Chen, R.,
Liu, S., Li, J., Ma, L., Liu, H., Zhou, Y., Zhao, J., Fang, X., Li, G., Fang, L., Li, Y., Liu, D., Zheng, H., Zhang, Y., Qin, N., Li, Z., Yang, G., Yang, S., Bolund, L., Kristiansen, K., Zheng, H., Li, S., Zhang, X., Yang, H., Wang, J., Sun, R., Zhang, B., Jiang, S., Wang, J., Du, Y., and Li, S. (2009). The genome of the cucumber, Cucumis sativus L. Nat. Genet. 41(12),1275-1281. https://doi.org/10.1038/ng.475.

Hurst, H.C. (1994). Transcription factors.1: bZIP proteins. Protein Profile 1, 123-168.

International Rice Genome Sequencing Project (2005). The mapbased sequence of the rice genome. Nature 436, 793-800. https:// doi.org/10.1038/nature03895.

Jakoby, M., Weisshaar, B., Dröge-Laser, W., Vicente-Carbajosa, J., Tiedemann. J., Kroj, T., and Parcy, F. (2002). bZIP transcription factors in Arabidopsis. Trends Plant Sci. 7, 106-111. https://doi. org/10.1016/S1360-1385(01)02223-3.

Jin, Z.W., Xu, W., and Liu, A.Z. (2014). Genomic surveys and expression analysis of bZIP gene family in castor bean (Ricinus communis L.). Planta 239, 299-312. https://doi.org/10.1007/s00425-013-1979-9.

Jing, Z.B., Yang, H.B., Yang, Y.W., Shen, J., Zhou, S.M., Yan, R.L., and $\mathrm{Xu}$, M. (2016). Isolation and identification of Pseudomonas syringae pv. Actinidiae in Northern Area of Qinling Mountains. J. Northwest Forestry University 31(5), 188-193 (in Chinese).

Kang, J.Y., Choi, H.I., Im, M.Y., and Kim, S.Y. (2002). Arabidopsis basic leucine zipper proteins that mediate stress-responsive abscisic acid signaling. Plant Cell 14, 343-357. https://doi.org/10.1105/ tpc. 010362 .

Koonin, E.V. (2005). Orthologs, paralogs, and evolutionary genomics. Annu. Rev. Genet. 39, 309-338. https://doi.org/10.1146/annurev. genet.39.073003.114725.

Letunic, I., Doerks, T., and Bork, P. (2012). SMART 7: recent updates to the protein domain annotation resource. Nucleic Acid Res. 40(D1), D302-D305. https://doi.org/10.1093/nar/gkr931.

Li, H., Gao, Y., Xu, H., Dai, Y., Deng, D.Q., and Chen, J.M. (2013). ZmWRKY33, a WRKY maize transcription factor conferring enhanced salt stress tolerances in Arabidopsis. Plant Growth Regul. 70, 207-216. https://doi.org/10.1007/s10725-013-9792-9.

Li, Y., Zhu, Y., Yao, J., Zhang, S., Wang, L., Guo, C., van Nocker, S., and Wang, X. (2017). Genome-wide identification and expression analyses of the homeobox transcription factor family during ovule development in seedless and seeded grapes. Sci. Rep. 7, 12638. https://doi.org/10.1038/s41598-017-12988-y.

Li, Y.Y., Meng, D., Li, M.J., and Cheng, L.L. (2016). Genome-wide identification and expression analysis of the bZIP gene family in apple (Malus domestica). Tree Genet. Genomes 12, 82. https://doi. org/10.1007/s11295-016-1043-6.

Liu, C., Wu, Y., and Wang, X. (2012). bZIP transcription factor OsbZIP52/RISBZ5: a potential negative regulator of cold and drought stress response in rice. Planta 235, 1157-1169. https://doi. org/10.1007/s00425-011-1564-z.

Meng, D., Li, Y., Bai, Y., Li, M., and Cheng, L. (2016). Genome-wide identification and characterization of WRKY transcriptional factor family in apple and analysis of their responses to waterlogging and drought stress. Plant Physiol. Biochem. 103, 71-83. https://doi. org/10.1016/j.plaphy.2016.02.006.

Nieva, C., Busk, P.K., Domínguez-Puigjaner, E., Lumbreras, V., Testillano, P.S., Risueño, M.C., and Pagès, M. (2005). Isolation and functional characterisation of two new bZIP maize regulators of the ABA responsive gene rab28. Plant Mol. Biol. 58, 899-914. https:// doi.org/10.1007/s11103-005-8407-x.

Nijhawan, A., Jain, M., Tyagi, A.K., and Khurana, J.P. (2008). Genomic survey and gene expression analysis of the basic leucine zipper 
transcription factor family in rice. Plant Physiol. 146, 333-350. https://doi.org/10.1104/pp.107.112821.

Paterson, A.H., Wang, X., Tang, H., and Lee, T.H. (2012). Synteny and genomic rearrangements. Plant. Gen. Diversity 1, 195-207. https:// doi.org/10.1007/978-3-7091-1130-7_13.

Rabara, R.C., Tripathi, P., Lin, J., and Rushton, R.J. (2013). Dehydrationinduced WRKY genes from tobacco and soybean respond to jasmonic acid treatments in BY-2 cell culture. Biochem. Biophys. Res. Commun. 431, 409-414. https://doi.org/10.1016/j.bbrc.2012.12.156.

Silveira, A.B., Gauer, L., Tomaz, J.P., Cardoso, P.R., Carmello-Guerreiro, S., and Vincentz, M. (2007). The Arabidopsis AtbZIP9 protein fused to the VP16 transcriptional activation domain alters leaf and vascular development. Plant Sci. 172, 1148-1156. https://doi.org/10.1016/j. plantsci.2007.03.003.

Song, H., Wang, P., Hou, L., Zhao, S., Xia, H., Li, P., Zhang, Y., Bian, X., and Wang, X. (2016). Global analysis of WRKY genes and their response to dehydration and salt stress in soybean. Front. Plant Sci. 7, 9. https://doi.org/10.3389/fpls.2016.00009.

Tak, H., and Mhatre, M. (2013). Cloning and molecular characterization of a putative bZIP transcription factor VvbZIP23 from Vitis vinifera. Protoplasma 250(1), 333-345. https://doi.org/10.1007/s00709012-0417-3.

Talanian, R.V., McKnight, C.J., and Kim, P.S. (1990). Sequence-specific DNA binding by a short peptide dimer. Science 249, 769-771. https://doi.org/10.1126/science.2389142.

Thurow, C., Schiermeyer, A., Krawczyk, S., Butterbrodt, T., Nickolov, K., and Gatz, C. (2005). Tobacco bZIP transcription factor TGA2.2 and related factor TGA2.1 have distinct roles in plant defense responses and plant development. Plant J. 44, 100-113. https://doi. org/10.1111/j.1365-313X.2005.02513.x.

Ulm, R., Baumann, A., Oravecz, A., Máté, Z., Ad, E., Oakeley, E.J., Schäfer, E., and Nagy, F. (2004). Genome-wide analysis of gene expression reveals function of the bZIP transcription factor HY5 in the UV-B response of Arabidopsis. Proc. Natl. Acad. Sci. USA 101, 1397-1402. https://doi.org/10.1073/pnas.0308044100.

Wang, J., Zhou, J., Zhang, B., Vanitha, J., Ramachandran, S., and Jiang, S.Y. (2011). Genome-wide expansion and expression divergence of the basic leucine zipper transcription factors in higher plants with an emphasis on sorghum. J. Integr. Plant. Biol. 53, 212-231. https:// doi.org/10.1111/j.1744-7909.2010.01017.x.

Wei, K., Chen, J., Wang, Y., Chen, Y., Chen, S., Lin, Y., Pan, S., Zhong, X., and Xie, D. (2012). Genome-wide analysis of bZIP-encoding genes in maize. DNA Res. 19, 463-476. https://doi.org/10.1093/dnares/ dss026.

Weltmeier, F., Ehlert, A., Mayer, C.S., Dietrich, K., Wang, X., Schütze, K., Alonso, R., Harter, K., Vicente-Carbajosa, J., and Dröge-Laser, W. (2006). Combinatorial control of Arabidopsis proline dehydrogenase transcription by specific hetero dimerisation of bZIP transcription factors. EMBO J. 25, 3133-3143. https://doi.org/10.1038/ sj.emboj.7601206.

Yáñez, M., Cáceres, S., Orellana, S., Bastías, A., Verdugo, I., Ruiz-Lara, S., and Casaretto, J.A. (2009). An abiotic stress-responsive bZIP transcription factor from wild and cultivated tomatoes regulates stress-related genes. Plant Cell Rep. 28, 1497-1507. https://doi. org/10.1007/s00299-009-0749-4.

Ying, S., Zhang, D.F., Fu, J., Shi, Y.S., Song, Y.C., Wang, T.Y., and Li, Y. (2012). Cloning and characterization of a maize bZIP transcription factor, ZmbZIP72, confers drought and salt tolerance in transgenic Arabidopsis. Planta 235, 253-266. https://doi.org/10.1007/s00425011-1496-7.
Zhang, X., Wollenweber, B., Jiang, D., Liu, F., and Zhao, J. (2008). Water deficits and heat shock effects on photosynthesis of a transgenic Arabidopsis thaliana constitutively expressing ABP9, a bZIP transcription factor. J. Exp. Bot. 59(4), 839-848. https://doi. org/10.1093/jxb/erm364.

Zhang, Y.C., Miao L., Wang, H., Brocker, C., Yin, X., Vasiliou, V., Fei, Z., and Wang, X. (2012). Genome-wide identification and analysis of grape aldehyde dehydrogenase (ALDH) gene superfamily. PLoS ONE 7, e32153. https://doi.org/10.1371/journal.pone.0032153.

Zhao, J., Guo, R., Guo, C., Hou, H., Wang, X., and Gao, H. (2016). Evolutionary and expression analyses of the apple basic leucine zipper transcription factor family. Front. Plant Sci. 7, 376. https:// doi.org/10.3389/fpls.2016.00376.

Zhao, Z.B., Gao, X.N., Yang, D.H., Huang, L.L., Qin, H.Q., Kang, Z.S., and Wang, N.N. (2015). Field detection of canker-causing bacteria on kiwifruit trees: Pseudomonas syringae pv. actinidiae is the major causal agent. Crop. Prot. 75, 55-62. https://doi.org/10.1016/j. cropro.2015.05.008.

Zou, M., Guan, Y., Ren, H., Zhang, F., and Chen, F. (2008). A bZIP transcription factor, OsABI5, is involved in rice fertility and stress tolerance. Plant. Mol. Biol. 66, 675-683. https://doi.org/10.1007/ s11103-008-9298-4.

Received: Apr. 26, 2018

Accepted: Jun. 6, 2018

Addresses of authors:

Zhaobin Jing ${ }^{1,2, *}$ and Hongqi $\mathrm{Fu}^{2}$

${ }^{1}$ College of Horticulture, Northwest A\&F University,

Yangling 712100, Shaanxi, China

${ }^{2}$ Weinan Vocational and Technical College, Weinan Fruit Industry Institute of Shaanxi, Weinan 714026, Shaanxi, China

* Corresponding author; E-mail: jingzhaobin@nwsuaf.edu.cn Tel.: +86-(0)913-303-3264 